Revue Revue de l'histoire des religions

del'histoire des religions

$4 \mid 2017$

Les discours sur les religions dans l'Empire romain : regards croisés entre " païens ", "juifs » et « chrétiens »

\title{
Les âges de l'Humanité et la critique du christianisme selon Damascius
}

The Ages of Humanity and the Critique of Christianity According to Damascius

Philippe Hoffmann

\section{OpenEdition}

Journals

Édition électronique

URL : http://journals.openedition.org/rhr/8832

DOI : $10.4000 /$ rhr.8832

ISSN : $2105-2573$

Éditeur

Armand Colin

Édition imprimée

Date de publication : 1 décembre 2017

Pagination : 737-775

ISBN : 978-2-200-93128-5

ISSN : 0035-1423

Référence électronique

Philippe Hoffmann, "Les âges de l'Humanité et la critique du christianisme selon Damascius », Revue de l'histoire des religions [En ligne], 4 | 2017, mis en ligne le 31 décembre 2019, consulté le 15 janvier 2021. URL : http://journals.openedition.org/rhr/8832 ; DOI : https://doi.org/10.4000/rhr.8832

Tous droits réservés 


\section{PHILIPPE HOFFMANN}

\section{École pratique des hautes études, PSL Research University, Paris \\ Laboratoire d'études sur les monothéismes (UMR 8584) \\ Laboratoire d'excellence Histoire et anthropologie \\ des savoirs, des techniques et des croyances \\ Les âges de l'Humanité et la critique du christianisme selon Damascius}

Damascius, chef de l'École néoplatonicienne d'Athènes (vie siècle) expose une philosophie de l'Histoire inspirée à la fois par Hésiode et par Platon, et liée à la théologie de l'École. Il distingue entre un âge de la Raison, ou "âge d'or »; un âge historique (la Grèce et Rome jusqu'au IV siècle), et un présent vil et détesté - l'Empire chrétien. L'âge d'or est la vie sous le règne de Cronos, assimilé par la théologie néoplatonicienne à un intellect divin, tandis que les passions dont souffre l'âme chrétienne ont pour horizon cosmologique le monde de la génération. Cette doctrine pourrait être reliée à la politique de Damascius à la tête de l'École, et avec le rêve illusoire de voir un philosophe-roi en Chosroès, le roi des Perses auprès de qui les philosophes se réfugièrent après 529.

\section{The Ages of Humanity and the Critique of Christianity According to Damascius}

Damascius, leader of the Neoplatonist School of Athens ( $\left.6^{\text {th }} C\right)$, exposes a philosophy of History that is inspired by both Hesiod and Plato, and linked to the theology of the School. He distinguishes between an age of reason or "golden age ", a historical age (Greece and Rome up to the $4^{\text {th }} \mathrm{C}$ ), and a vile and hateful present - the Christian Empire. The golden age was life under the reign of Cronos, whom Neoplatonist theology assimilates with a divine intellect, whereas the cosmological horizon of the passions afflicting the Christian soul is the realm of generation. This doctrine could be related to Damascius' own political views as head of the School, and to an illusory dream of finding a philosopher-king in Khosrow, king of the Persians, with whom the philosophers sought refuge after 529. 
Le document que l'on va étudier dans ces pages correspond - comme le veut le thème de la rencontre organisée par Francesco Massa - à un discours philosophique néoplatonicien construit au début du $\mathrm{VI}^{\mathrm{e}}$ siècle, au sujet non pas du christianisme comme corpus de croyances ou de doctrines théologiques - aspect presque complètement ignoré par les philosophes néoplatoniciens ${ }^{1}-$, mais de ce que l'on pourrait appeler le christianisme "réel», en tant que réalité sociale et politique - détestée on le sait par les derniers païens. Il s'agit d'un texte de Damascius, dernier diadoque de l' «Académie » platonicienne à Athènes ${ }^{2}$, appartenant à la Vie d'Isidore, ouvrage où Damascius brosse un panorama du paganisme philosophique du $\mathrm{V}^{\mathrm{e}}$ siècle, en même temps qu'un portrait de son maître, le philosophe Isidore d'Alexandrie ${ }^{3}$. La Vie d'Isidore est conservée de façon fragmentaire dans le codex 242 de la Bibliothèque de Photius ${ }^{4}$ lequel ne semble pas avoir eu connaissance de l'œuvre proprement philosophique

* Je souhaite dédier ces pages à la mémoire de mon élève et ami Stéphane Diebler, enseignant à l'École normale supérieure, qui avait entrepris une thèse de doctorat à l'EPHE sur la Vie d'Isidore. Toujours vif est le souvenir de nos échanges autour de cette œuvre qu'il connaissait si bien, et qu'il avait traduite dans son mémoire de DEA en 1994. - Cette étude prend la suite d'une recherche antérieure, «Un grief anti-chrétien chez Proclus : l'ignorance en théologie », dans Arnaud Perrot, éd. Les chrétiens et l'hellénisme. Identités religieuses et culture grecque dans l'Antiquité tardive, Paris, Éditions Rue d'Ulm («Études de littérature ancienne », 20), 2012, p. 161-197, où j'avais déjà eu l'occasion d'évoquer le texte de Damascius (p. 161-163 et 197). Il m'est agréable de remercier une nouvelle fois la Fondation Hardt pour l'étude de l'Antiquité classique (Vandœuvres/Genève), pour les remarquables conditions de travail qu'elle offre aux chercheurs.

1. Voir «Un grief anti-chrétien chez Proclus », p. 161-162.

2. Voir Philippe Hoffmann, article «Damascius», dans Richard Goulet, éd. Dictionnaire des Philosophes Antiques [DPhA], II, Paris, CNRS éditions, 1994, D3, p. 541-593. - Il convient de rappeler qu'il n'y a pas de continuité historique entre l'Académie de Platon et l'école néoplatonicienne de l'Antiquité tardive, comme l'a bien montré John Glucker, Antiochus and the Late Academy (Hypomnemata, 56), Göttingen 1978, spéc. p. 248-255 et 322-329.

3. Voir R. Goulet, article "Isidore d'Alexandrie», DPhA, III, Paris 2000, I 31, p. 870-878.

4. Voir l'édition de René Henry, Photius. Bibliothèque, VI, Paris, Les Belles Lettres, 1971, p. 8-56 (335 a 20-353 a 20 Bekker), et la publication récente de Fozio. Biblioteca, introduzione di Luciano Canfora, nota sulla tradizione manoscritta di Stefano Micunco, a cura di Nunzio Bianchi e Claudio Schiano, Pise, Edizioni della Normale, 2016, p. 584-615. 
de Damascius ${ }^{5}$-, et dans une série de notices de l'encyclopédie byzantine de la Souda ${ }^{6}$. L'ouvrage, écrit alors que Théodoric régnait en Italie (493-526), et peut-être après la mort du philosophe Ammonius d'Alexandrie (disparu après 517), excède largement, par ses développements, le genre de la biographie, et se démarque nettement - et sans doute intentionnellement - de l'éloge de

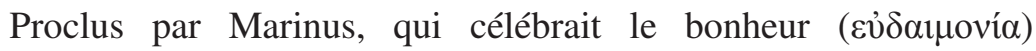
auquel était parvenu le philosophe par la réalisation des vertus néoplatoniciennes ${ }^{7}$. Il est connu sous deux titres, ou du moins deux appellations: d'une part comme «Vie d'Isidore» (ßíos,

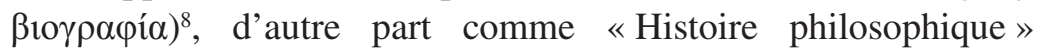

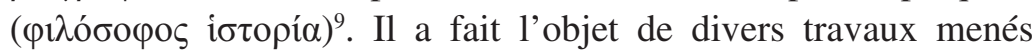
au $\mathrm{XX}^{\mathrm{e}}$ siècle par des philologues, des historiens, et des historiens de la philosophie, depuis le travail pionnier de reconstitution tenté par Rudolf Asmus en 1909-1911 10, et l'on dispose pour l'étudier

5. Photius, dans la Bibliothèque, ne nous donne de notices que sur le recueil paradoxographique de Damascius (codex 130, voir DPhA, II, D 3, p. 565-566) et sur la Vie d'Isidore (codices 181 et 242), dont il souligne la virulence antichrétienne, mais il ne fait aucune allusion au Traité des premiers principes ni aux commentaires sur Platon, transmis par les Marciani graeci 196 et 246 de la «Collection philosophique » (sur laquelle voir infra, note 45).

6. Voir les articles «Damascius», DPhA, II, p. 566-570, et «Isidore d'Alexandrie », DPhA, III, p. 870-872; et infra, note 17.

7. Voir Marinus, Proclus ou Sur le bonheur, édité par Henri Dominique Saffrey et Alain-Philippe Segonds (avec la collaboration de Concetta Luna), Paris, Les Belles Lettres (CUF), 2001 ; et DPhA, II, p. 568.

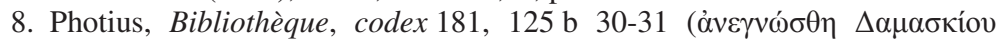

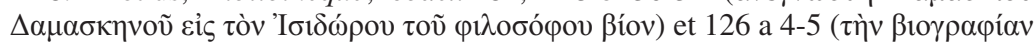

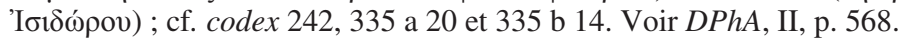

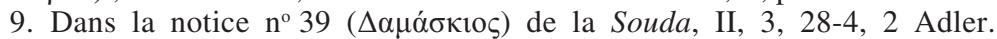
Voir DPhA, II, p. 567. C'est le titre retenu par Polymnia Athanassiadi, Damascius. The Philosophical History, Athènes 1999 [texte grec et traduction en anglais], voir p. 39-42, 58-60, qui justifie cette préférence par une analyse du genre littéraire de l'ouvrage, et considère cette œuvre non comme une biographie d'Isidore, mais comme un ensemble organique émergeant d'un désordre accentué par la pratique des digressions et les conditions de la transmission : «As I reassembled the pieces of the jigsaw puzzle left by Photius and the Suda, I increasingly saw how all this disparate material - the patria and paradoxa, the lives of the pagan intelligentsia against a background of persecution and martyrdom, the history of the Platonic succession, and the story of Damascius' conversion to philosophy - formed more of an organic whole than had ever been realised before » (p. 60).

10. Rudolf Asmus, "Zur Rekonstruktion von Damascius' Leben des Isidorus », Byzantinische Zeitschrift, 18, 1909, p. 424-480 [première partie], et 19, 1910, p. 265-284 [seconde partie] ; et Das Leben des Philosophen Isidoros, von Damaskios aus Damaskos, coll. « Der Philosophischen Bibliothek », Bd 125, 
d'une édition critique dans laquelle Clemens Zintzen (1967), sans chercher à reconstituer un état originel du texte de Damascius, permet de confronter les deux - ou même trois - états conservés du texte, en donnant d'un côté, sur la page de gauche, la première série des extraits de Photius («Epitoma Photiana ») et en face, sur la page de droite, la deuxième série des extraits de Photius, et surtout les extraits transmis par la Souda («Fragmenta ») ${ }^{11}$. Cette édition, qui est tributaire à bien des égards de la reconstruction d'Asmus, offre néanmoins une base philologique très utile pour toute recherche sur la Vie d'Isidore.

\section{L'EXPosé de Damascius SUR les TROIS ÂGes de l'Humanité : L'ÉTAT DU TEXTE}

L'on voudrait ici s'arrêter sur un «fragment » particulièrement important, pour lequel nous disposons déjà d'un beau commentaire du P. Henri Dominique Saffrey ${ }^{12}$. Le texte nous a été transmis sous plusieurs formes sensiblement différentes, dont la comparaison, riche d'enseignement philologique, montre le caractère très problématique de la notion même de «fragment», et la difficulté des tentatives de reconstruction du texte originel, comme celles

Leipzig, Felix Meiner, 1911. On lira avec intérêt la présentation de la méthode suivie par Asmus (qui a tenté d'organiser les fragments autour du projet d'une biographie d'Isidore), dans P. Athanassiadi, Damascius. The Philosophical History, p. 63-64.

11. Clemens Zintzen, Damascii Vitae Isidori reliquiae edidit adnotationibusque instruxit C.Z., coll. «Bibliotheca graeca et latina suppletoria»1, Hildesheim, Olms, 1967, XIV-376 p. Dans cette édition, certains fragments provenant de la Souda sont marqués par un astérisque et ne sont attribués à Damascius que de façon conjecturale ( Stellula significavi fragmenta Damascio coniectura attributa », p. XIV). Le compte rendu critique de René Henry, dans la Revue belge de philologie et d'histoire, 46, 1968, p. 853-858, en souligne la qualité, en dépit de nombreuses fautes dans la lecture des manuscrits. - Sur les éditions et traductions de la Vie d'Isidore, voir DPhA, II, p. 567-568 (on ajoutera à présent l'édition de Polymnia Athanassiadi citée supra, note 9).

12. Henri Dominique Saffrey, «Le thème du malheur des temps chez les

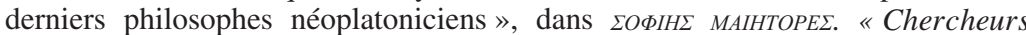
de sagesse ». Hommage à Jean Pépin (coll. des Études augustiniennes. Série Antiquité. 131), Paris 1992, p. 421-431; article repris dans Le néoplatonisme après Plotin (coll. «Histoire des doctrines de l'Antiquité classique », 24), Paris 2000, p. 207-217 ; spéc. p. 424-426 [210-212] : traduction et commentaire des fragments de la Vie d'Isidore. 
de Rudolf Asmus (1911) et de Polymnia Athanassiadi (1999) ${ }^{13}$. Dans le codex 242, le patriarche Photius a prêté attention à deux reprises à notre texte, dont il donne une version «brève » (fr. 22) et une version «longue » (fr. 238) dans une deuxième série d'extraits

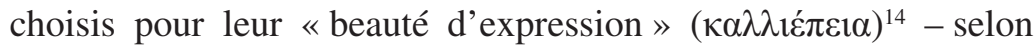
un procédé que l'on observe aussi dans le codex 241 consacré à la Vie d'Apollonios de Tyane par Philostrate ${ }^{15}$. Même dans leur section commune, le deuxième extrait (fr. 238) n'offre pas un texte rigoureusement identique au premier (fr. 22). Il est certain que, dans la seconde série d'extraits, Photius ne s'intéressait pas uniquement à la forme littéraire du texte de Damascius, mais aussi au contenu même, ce qui explique sans doute qu'il ait décidé alors de reproduire - ou d'adapter - la version complète de l'exposé sur les trois âges de l'Humanité, même si la richesse du vocabulaire, des images et des allusions littéraires chez l'écrivain Damascius justifient le jugement

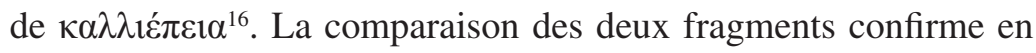

13. R. Asmus, Das Leben des Philosophen Isidoros, p. 13-14 ; et P. Athanassiadi, Damascius. The Philosophical History, fragment 18 aux p. 96-97 (spéc. note 45 aux p. 97 et 99).

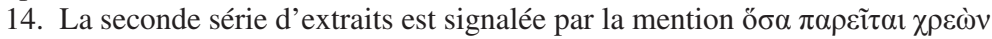

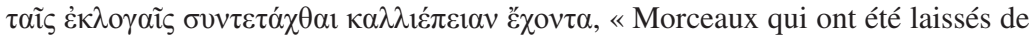
côté et qu'il faut ajouter aux extraits pour la beauté de leur expression » (349 b 13-14; Henry, t. VI, p. 46). Lire la note de Henry (t. VI, p. 207), qui établit à partir du rapprochement avec le codex 241 (voir la note suivante) que les deux séries d'extraits sont dues à Photius lui-même, et non à un reviseur de la Bibliothèque (contre l'opinion de R. Asmus, «Zur Rekonstruktion von Damascius' Leben des Isidorus », ByzZ, 18, 1909, p. 426-427). Voir aussi P. Athanassiadi, Damascius. The Philosophical History, p. 61.

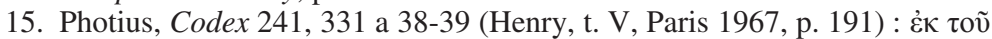

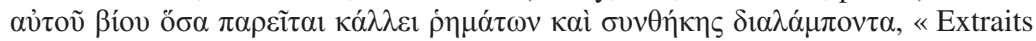
de la même biographie qui ont été laissés de côté et qui se signalent par la beauté des mots et des tournures ». Lire la longue note de Henry (t. V, p. 228-229) sur la technique de Photius, dont l'étude est, dans le cas de la Vie d'Apollonios de Tyane, facilitée par la possibilité de mener une comparaison entre le texte original de Philostrate, qui est conservé, et les extraits de Photius, ce qui n'est évidemment pas le cas pour la Vie d'Isidore.

16. La méthode de travail de Photius dans les codices 44 et 241 (Philostrate) a été étudiée de façon approfondie par Tomas Hägg, Photios als Vermittler antiker Literatur. Untersuchungen zur Technik des Referierens und Exzerpierens in der Bibliotheke, Uppsala, Almquist \& Wiksell International («Acta Universitatis Upsaliensis. Studia Graeca Upsaliensia », 8), 1975, p. 15-124, qui compare dans le cod. 241 les Sachexzerpte (première série d'extraits, 323 b 33-331 a 37, voir p. 24-35) et les Stilexzerpte (seconde série d'extraits, 331 a 38-335 a 19, voir p. 35-39), et conclut qu'il n'y a pas en fait de différence nette entre les deux : «Es existiert also in der Praxis keine absolute Abgrenzung zwischen 
tout cas que l'excerpteur ne s'astreignait pas toujours à reproduire avec une parfaite précision le texte qu'il copiait ou adaptait. Et l'on ne peut non plus évaluer le degré d'exactitude du texte, plus long que les deux « extraits » de Photius, que l'on reconstitue à partir de trois articles de la Souda, qui peuvent sans hésitation être recollés comme les pièces d'un puzzle (mais là encore, avec de légères

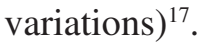

Ce texte philologiquement instable, en raison de sa transmission multiple, expose clairement ce que l'on pourrait appeler une " philosophie néoplatonicienne de l'Histoire », ou une théorie des « Âges de l'Humanité », selon une consécution chronologique et un schéma de dégradation qui font se succéder : un temps - mythique -

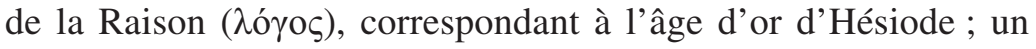
temps - héroïque et proprement historique - du principe Irascible $(\theta v \mu o ́ s)$ et des activités guerrières, qui est, en termes platoniciens, le temps du courage ( $\alpha v \delta \rho \varepsilon i ́ \alpha)$ et de la recherche des honneurs

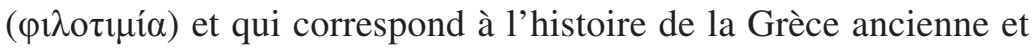
de la Rome païenne jusqu' au IV $V^{\mathrm{e}}$ siècle ; et enfin un temps présent (vṽv) dominé par le principe Concupiscible, et où s'exprime toute la détestation de Damascius pour le régime politique byzantin

Sach- und Stilexzerpten. Die letzteren wirken gewissermassen als Ergänzungen zu den vorigen, auch im Hinblick auf den Inhalt. Ein wichtiger Unterschied ist jedoch, dass die Stilexzerpte nicht in zusammenhängenden Abschnitten gegeben sind ; der Exzerptor bemüht sich überhaupt nicht, sie miteinander zu verbinden. Die Grenze wird übrigens nicht nur in einer Richtung überschritten; es darf vermutet werden, dass die Sachexzerpte auch wegen der Formulierungskunst des Philostratos Photios angezogen haben » (p. 39). Ces remarques, formulées au sujet du codex 241, sont probablement valables aussi pour le codex 242. Sous réserve évidemment d'une étude des deux séries d'extraits du codex 242, avec une comparaison des deux codices (241 et 242), on accordera donc une égale importance aux deux «extraits » de la Vie d'Isidore donnés par Photius. C'était déjà en substance l'opinion de R. Asmus, "Zur Rekonstruktion... », ByzZ, 18, 1909, p. 426 : «Hinter 230 findet sich die Bemerkung : ő $\sigma \alpha \kappa \tau \lambda$., wonach man in den folgenden Nummern einen aus stilistischen Gründen gefertigten Nachtrag zu den vorausgehenden zu erblicken hätte. Dem ist aber nicht so. Vielmehr ist auch weiterhin für den Exzerptor nicht ausschließlich das formale Interesse, sondern auch der Inhalt maßgebend gewesen, und zudem enthält die angebliche Ergänzung eine ganze Anzahl von Fragmenten, welche bereits in der Anfangspartie vorkommen ».

17. Ada Adler, éd. Suidae Lexicon, Pars IV (П-Ч), Leipzig, Teubner, 1935,

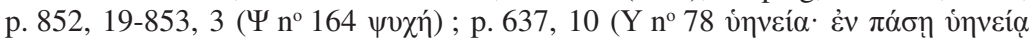

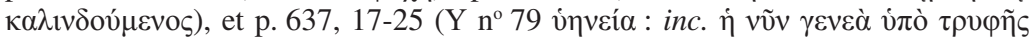

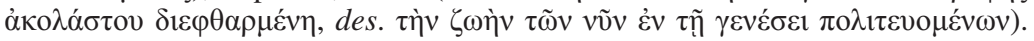
Voir Zintzen p. 27 (note au Fragment 30a, p. 27, 3-31, 7). 
et la société corrompue qui l'entoure. Le schème hésiodique du mythe des races ${ }^{18}$ (Hésiode étant toujours lu et commenté dans l'Antiquité tardive, comme le montre le commentaire de Proclus $)^{19}$ et la tripartition caractéristique de la psychologie platonicienne - celle de la République - se conjuguent pour brosser une histoire de la décadence morale et politique de l'Humanité, qui pour Damascius, ici, coïncide avec le monde grec. Dans la description de la période présente, celle de l'Empire chrétien, Damascius déploie une rhétorique de l'invective, en accumulant des termes et des épithètes violemment dépréciatifs, qui relèvent pour l'essentiel de la disqualification morale et qui, d'un point de vue littéraire, illustrent l'art de l'écrivain et ont retenu toute l'attention de Photius.

Par souci de clarté, nous commencerons par reproduire les trois versions de l'exposé sur les âges de l'Humanité, en annotant la version «longue» de Photius, et la notice de la Souda ${ }^{20}$. La comparaison attentive des diverses versions en grec permet de repérer des mots et des expressions identiques qui doivent conserver avec fidélité la rédaction même de Damascius, faisant apparaître par là-même les libertés prises par les excerpteurs.

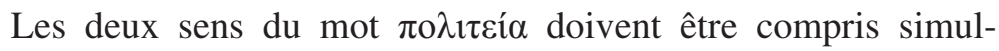
tanément et le français offre aussi le mot «régime», qui peut

18. À propos duquel on relira avec fruit, en dépit de l'écart immense entre le poète archaïque et le « diadoque platonicien », les études classiques de Jean-Pierre Vernant (qui donnent accès à l'essentiel de la bibliographie antérieure) : « Le mythe hésiodique des races. Essai d'analyse structurale », «Le mythe hésiodique des races. Sur un essai de mise au point » [réponse à des critiques de Jean Defradas], et « Méthode structurale et mythe des races » [en hommage à Victor Goldschmidt], repris dans Jean-Pierre Vernant, Euvres. Religions, rationalités, politique, I, Paris, Éditions du Seuil, 2007, p. 255-334 : le mythe, que Vernant organise notamment à l'aide de la tripartition fonctionnelle indo-européenne (G. Dumézil, voir p. 276 et

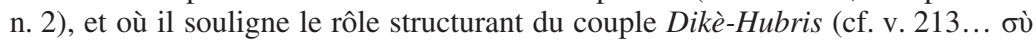

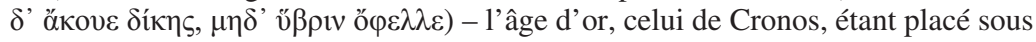
le signe de la Justice -, porte une opposition qui demeure intéressante pour notre lecture de Damascius : «L'or et l'argent se rattachent à la fonction de souveraineté qui assure le bon exercice de la justice entre les hommes et le respect de la piété envers les dieux ; bronze et héros se situent entièrement dans le champ de l'activité militaire, vouée à la guerre et aux combats » (p. 317) - cette dimension militaire et

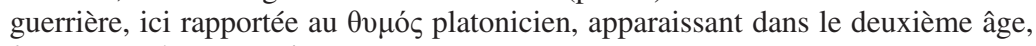
historique, de Damascius.

19. Voir infra, p. 755-757, et note 72.

20. Je me suis inspiré très librement des traductions de R. Henry et H.D. Saffrey, en m'en éloignant souvent. 
s'entendre du genre de vie (ici, en un sens non médical) et du régime politique ${ }^{21}$.

\section{Extrait 22 Photius ${ }^{22}$}

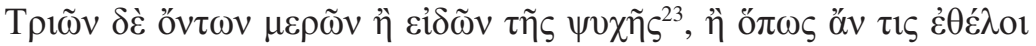

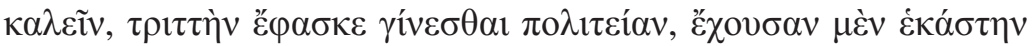

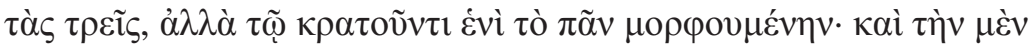

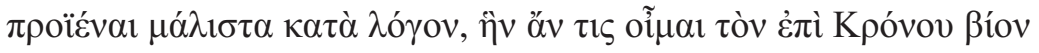

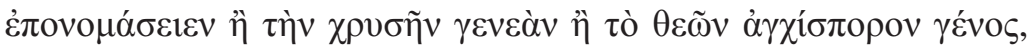

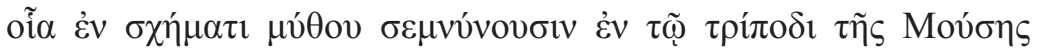
$\kappa \alpha \theta \eta \dot{\mu \varepsilon v o l ~ \pi o ı \eta \tau \alpha i ́ . ~}$

«Puisqu'il y a trois parties dans l'âme ou qu'il y en a trois aspects - quelque terme qu'on veuille employer - il [Isidore ?] avait accoutumé de dire qu'il existe un triple régime de vie ${ }^{24}$, dont

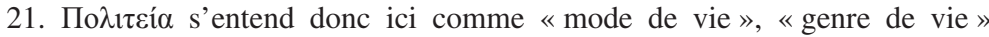
(cf. G.W.H. Lampe, A Patristic Greek Lexicon, Oxford, 1961, p. 1113-1114, s.v. $\pi \mathrm{o} \lambda \iota \tau \varepsilon i ́ \alpha, \mathrm{F}$ «way of life »; et Du Cange, Glossarium ad scriptores mediae et infimae Graecitatis, Lyon 1688, réimpr. Graz 1958, col. 1194 : "vitae ratio »), et comme «régime politique » fondé sur ce «mode de vie », conformément à l'analogie de la République de Platon entre les $\ddot{\eta} \theta \eta$ et les constitutions politiques.

22. p. 336 b 13-21 Bekker ; Henry, t. VI, p. 12 ; Zintzen p. 26 ; Canfora p. 587. - Voir infra, les notes 26-28.

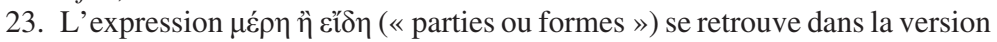
de la Souda, tandis que le fr. 238 Photius ne mentionne que des $\varepsilon$ i $\delta \eta$ (cf. Platon,

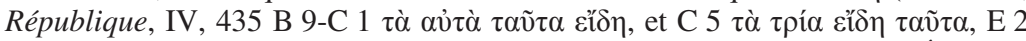

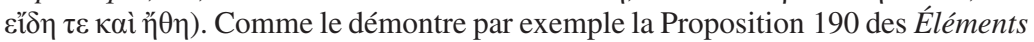
de Théologie de Proclus (éd. Dodds, p. 166, 1-25), l'âme est intermédiaire entre les réalités indivisibles ( $\tau \grave{\alpha} \alpha \dot{\alpha} \mu \varepsilon^{\prime}(\sigma \tau \alpha)$ et « celles qui se divisent dans les corps »

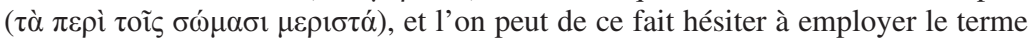
$\mu \varepsilon \dot{p} \eta$. Mais on le rencontre chez Proclus dans son commentaire sur Rép. IV, par

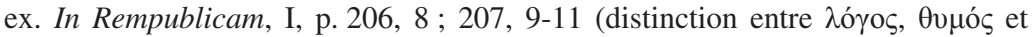

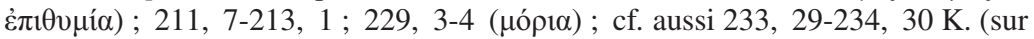
l'unité de l'âme selon Platon, compatible avec la tripartition). La division de l'âme en trois est décrite aussi, dans le cadre d'une analogie qui fait se correspondre

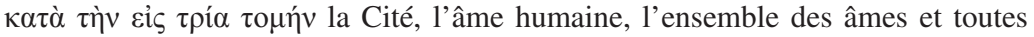
les réalités encosmiques, dans l'In Timaeum, I, p. 33, 28-34, 3 Diehl (traduction A.-J. Festugière, Proclus. Commentaire sur le Timée, I, Paris 1966, p. 65-66).

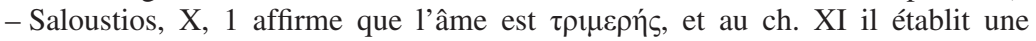
correspondance entre la tripartition de l'âme et les trois types de gouvernement

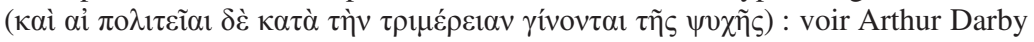
Nock, Sallustius concerning the Gods and the Universe, Cambridge, University Press, 1926, p. LXXVI et note 165, p. 20, 15 et 22, 1-2.

24. $\mathrm{Ou}:$ «trois types de régimes politiques ». 
chacun contient les trois régimes, mais dans son ensemble reçoit sa forme du seul régime qui prédomine. Le premier procède surtout conformément à la Raison ; c'est celui qu'on pourrait nommer, je crois, la vie au temps de Cronos, ou l'âge d'or, ou "la race [des hommes] parente des dieux", que célèbrent sous forme de fables les poètes assis sur le trépied de la Muse ».

\section{Extrait 238 Photius $^{25}$}

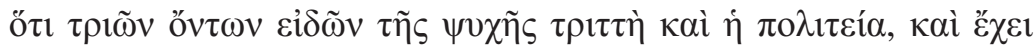

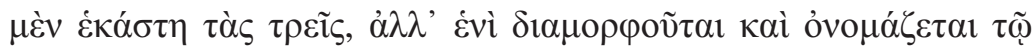

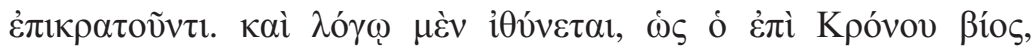

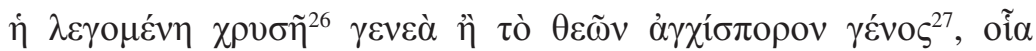

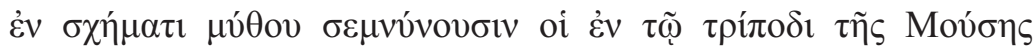

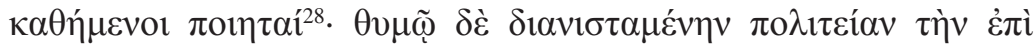

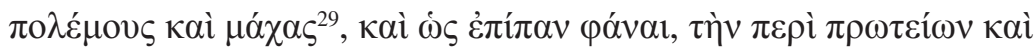

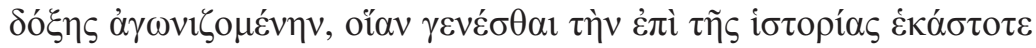

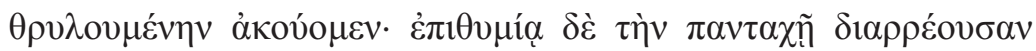

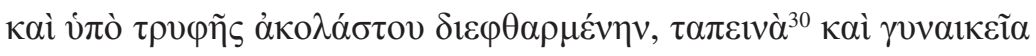

25. p. 350 a 5-20 Bekker; Henry, t. VI, p. 47-48 ; Zintzen p. 27-31 (Epitoma Photiana 238 = fragment 30 Z.) ; Canfora p. 609-610.

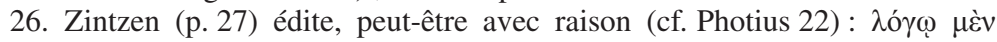

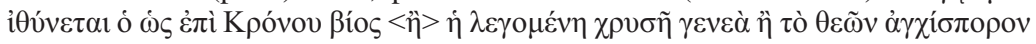
$\gamma \varepsilon ́ v o \zeta$, ce qui se comprend : « Est régie par la Raison la vie qui est comme au temps de Cronos, ou encore ce que l'on appelle l'âge d'or, ou bien la race [des hommes] parente des dieux $»$.

27. Reformulation des premiers mots d'un fragment de la Niobé d'Eschyle (oi

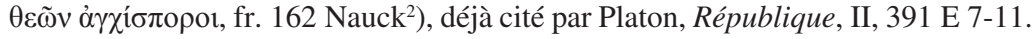
Voir l'édition de Stefan Radt, Tragicorum Graecorum Fragmenta, 3 : Aeschylus, Göttingen, Vandenhoeck \& Ruprecht, 1985, fr. 162, p. 277-278, qui rassemble l'ensemble des témoignages sur ce fragment.

28. Cette expression imagée est une imitation de Platon, Lois, IV, 719 C 3-4

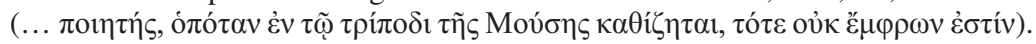
Elle n'a pas été reproduite par la Souda.

29. Cet âge du $\theta 0 \mu$ ó $\varsigma$ n'est pas sans évoquer la race de bronze et celle des héros (Hésiode, Travaux, v. 143-173): les premiers ne songent qu'aux

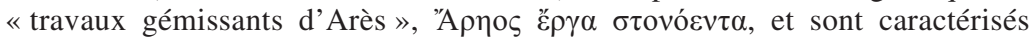
par l'v̋ß $\beta ı \varsigma$ (v. 145-146); les autres manifestent plus de justice (v. 158). Parmi les héros, Hésiode mentionne les guerriers morts devant les murs de Thèbes

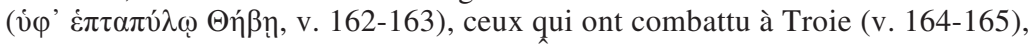
et enfin ceux qui ont été installés aux « Iles des Bienheureux » (v. 171). Voir supra, note 18 .

30. Le contraire de la «grandeur d'âme » à laquelle doit s'efforcer le philosophe. 


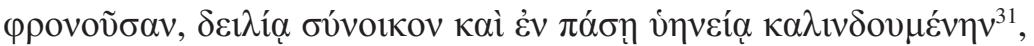

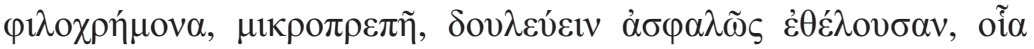

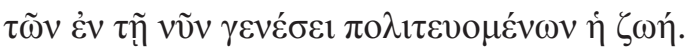

« Puisqu'il y a trois aspects dans l'âme, il y a aussi un triple régime de $v^{32}{ }^{32}$ : sans doute chacun contient les trois régimes, mais il reçoit sa forme et son nom du seul régime qui prédomine. Est régi par la Raison - comme la vie au temps de Cronos - ce que l'on appelle l'âge d'or, ou bien "la race [des hommes] parente des dieux", que célèbrent sous forme de fables les poètes assis sur le trépied de la Muse. Est inspiré par l'Irascible, le régime qui se précipite vers les guerres et les combats et qui, en général, lutte pour les premiers rangs et pour la gloire, comme nous entendons dire qu'a été celui dont on parle en toute occasion dans l'Histoire. Est gouverné par le Concupiscible, le régime qui se répand de tous côtés, qui est corrompu par une jouissance intempérante, qui n'a que des pensées basses et indignes d'un homme, qui est inséparable de la lâcheté, qui se vautre dans toute espèce de fange, qui est avide de richesses, qui est mesquin, qui ne veut que la sécurité de l'esclavage, telle la vie que mènent les hommes de la génération de maintenant ».

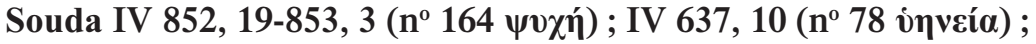
$637,17-25$ ( $\mathrm{n}^{\circ} 79$ ínvé́a)

Nous reproduisons ici le texte de la notice $\psi v \chi \eta ́$, en indiquant en note les variantes mineures présentées par les deux notices v́nveía ( « grossièreté », litt. " porcherie », « cochonnerie ») :

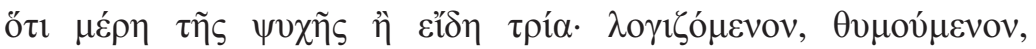

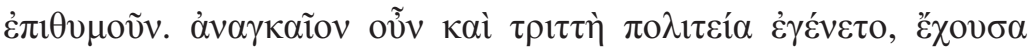

31. Expression inspirée de Platon, Politique, 309 A 5-6, en liaison avec l'idée

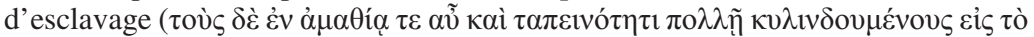

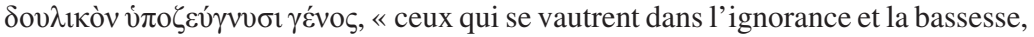
[la science royale] les soumet au joug de l'esclavage »), ou du Phédon, 82 E 4-5

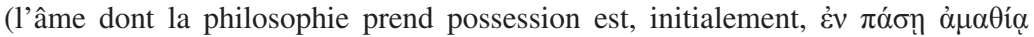

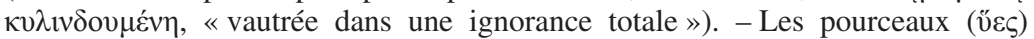
sont un motif fréquent dans les injures, ou du moins les formules dépréciatives

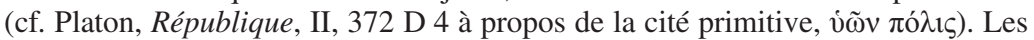
porcs se plaisent au bourbier, ßó $\rho \beta$ opos (cf. Plotin, Traité 1 [I, 6], 6, 1-6, suivant Platon, Phédon, 69 C 1-7, et Héraclite, fragment B 13 DK).

32. $\mathrm{Ou}:$ «trois types de régimes politiques ». 


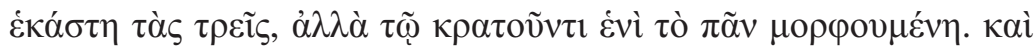

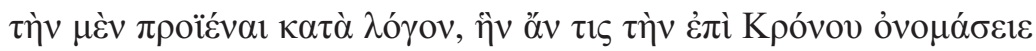

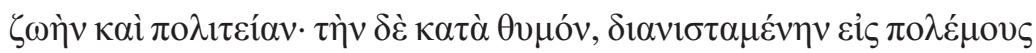

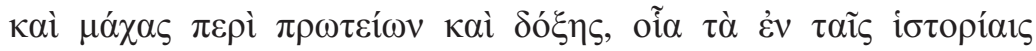

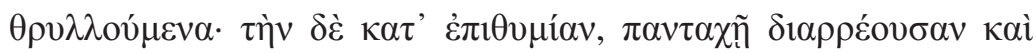

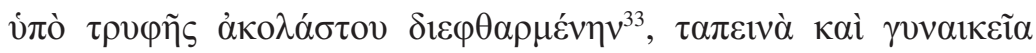

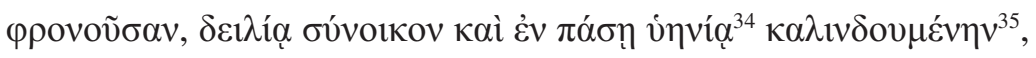

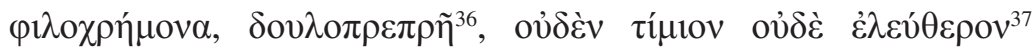

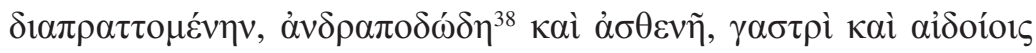

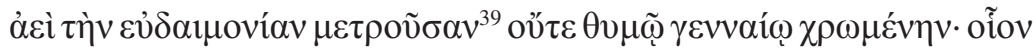

33. Ici commence le parallèle avec la notice v́nveía (Souda IV, 637,

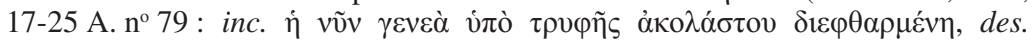

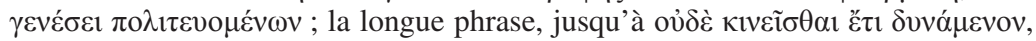
est au nominatif).

34. Les deux autres notices ( $\mathrm{n}^{\circ} 78$ et 79$)$ présentent la forme vinveía.

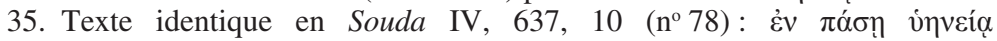

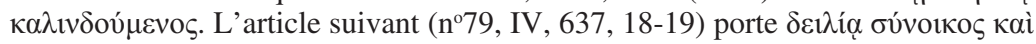

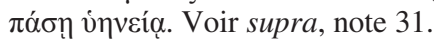

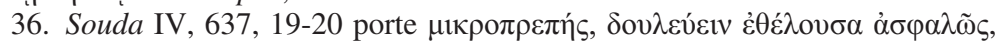

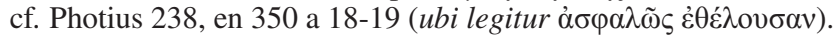

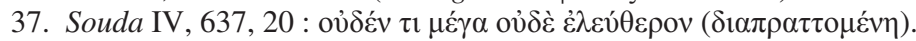

38. Mot plusieurs fois utilisé par Platon : Alcibiade I, 120 B 2-3 (la «tonsure

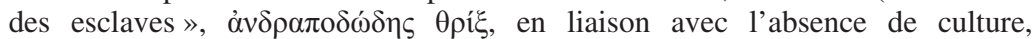

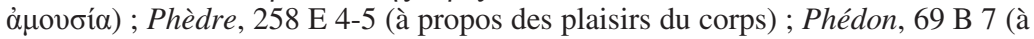

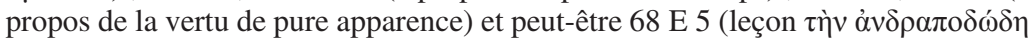

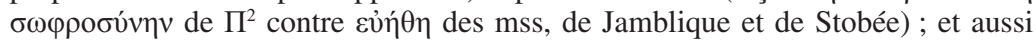

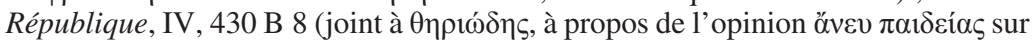

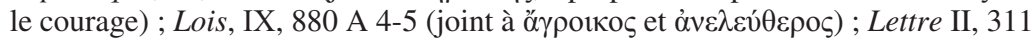

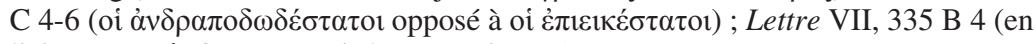

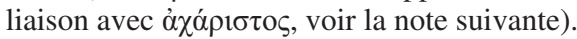

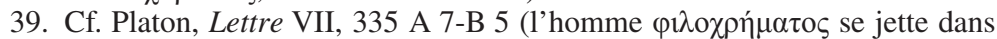
la gloutonnerie et l'intempérance sexuelle); Phédon, 81 B 5-6; mais surtout ici Démosthène, Sur la couronne, 296 (contre les traîtres semblables à Eschine) :

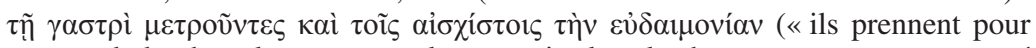
mesure du bonheur leur ventre et leurs parties les plus honteuses », et ont renoncé à la liberté). Ce thème d'invective rappelle aussi un fragment de Lycurgue conservé en traduction latine par le grammairien Rutilius Lupus (Cuius omnes corporis partes ad nequitiam sunt appositissimae : oculi ad petulantem lasciviam, manus ad rapinam, venter ad aviditatem, [virilis naturae secl.] membra, quae non possumus honeste appellare, ad omne genus corruptelae, pe $\langle d e>s$ ad fugam etc.) que Félix Durrbach (éd. Lycurgue. Contre Léocrate. Fragments, Paris, CUF, 1932 [19562], p. 93, fr. VIII, $4^{*}=$ Blass 61) pensait peut-être provenir du Contre Céphisodote sur les honneurs décernés à Démade (voir F. Durrbach, L'orateur Lycurgue. Étude historique et littéraire [BEFAR 57], Paris, Ernest Thorin, 1890, p. 144-147), mais qui est désormais classé parmi les fragments d'origine incertaine par le récent éditeur Nicos C. Conomis, Lycurgi Oratio in Leocratem, cum ceterarum Lycurgi orationum fragmentis, Leipzig, Teubner, 1970, p. 119 


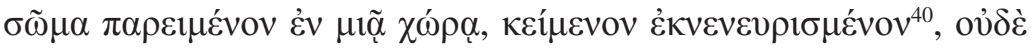

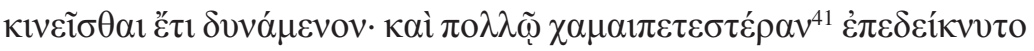

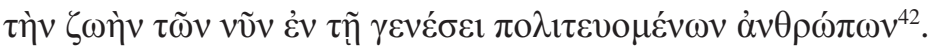

«Il y a trois parties ou aspects dans l'âme : ce qui raisonne, ce qui est irascible, ce qui désire. Il fallait donc bien qu'il y eût aussi un triple régime de vie, chacun contenant les trois régimes mais recevant sa forme, dans son ensemble, du seul régime qui prédomine. Et le premier régime procède selon la Raison: on pourrait l'appeler la vie et le régime au temps de Cronos. Le deuxième procède selon l'Irascible et se précipite sur les guerres et les combats pour les premiers rangs et pour la gloire, ainsi qu'on en parle sans cesse dans les histoires. Le troisième procède selon le Concupiscible : il se répand de tous côtés, il est corrompu par une jouissance intempérante, il n'a que des pensées basses et indignes d'un homme, il est inséparable de la lâcheté et se vautre dans toute espèce de fange, il est avide de richesses, servile, il n'accomplit rien d'estimable ni de libre, il est digne d'un esclave et débile, il règle toujours son bonheur sur son ventre et sur son sexe et ne fait jamais montre d'un noble cœur ; il est comme un corps abandonné quelque part, gisant énervé et incapable de se mouvoir encore; et c'est sous des couleurs plus viles encore que [Damascius] représentait la vie des hommes qui maintenant mènent leur existence dans le monde de la génération ».

(XV. 6). - Dans le traité de Rutilius Lupus sur les figures de rhétorique, De figuris sententiarum et elocutionis, ce fragment de Lycurgue illustre la figure dite $\mu \varepsilon \rho 1 \sigma \mu o ́ \varsigma$ [I 18] : « Hoc schema singulas res separatim disponendo et suum cuique proprium tribuendo magnam efficere utilitatem et illustrem consuevit». Voir les éditions de : Giuseppina Barabino, P. Rutilii Lupi. Schemata Dianoeas et Lexeos, Gênes, Istituto di Filologia Classica e Medioevale, 1967, p. 172 ; Edward Brooks Jr., P. Rutilii Lupi. De figuris sententiarum et elocutionis (Mnemosyne. Suppl. 11), Leyde, Brill, 1970, p. 22.

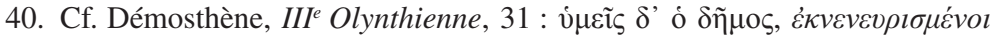

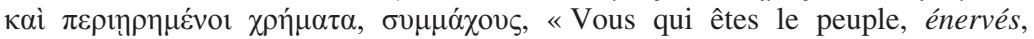
dépouillés de votre argent, de vos alliés...».

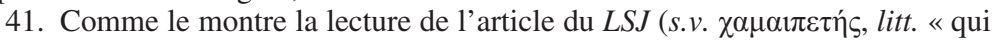
est tombé à terre »), Damascius a également choisi ici un mot bien attesté dans la littérature grecque classique (Pindare, Eschyle, Euripide, Platon).

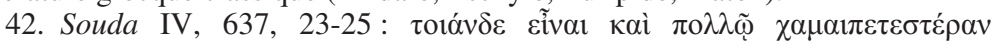

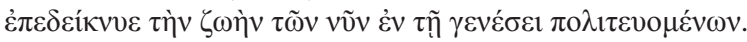




\section{Damascius, Hésiode et Platon : L'histoire humaine SELON UN SCHÈME DE DÉGRADATION}

Damascius croise deux références fondamentales: les Travaux d'Hésiode - commentés par Proclus - et la République de Platon, qui, sans appartenir expressément au « canon de Jamblique » qui régissait l'enseignement néoplatonicien ${ }^{43}$, était évidemment lue et commentée à Athènes comme à Alexandrie: le commentaire de Proclus, là encore, en est une preuve éclatante et l'on sait que Damascius - restaurateur de l'ensemble du cursus philosophique néoplatonicien dans l'école d'Athènes - a peut-être lui-même consacré des cours à la République ${ }^{44}$. Cet immense dialogue nous a par ailleurs été transmis par le Parisinus graecus 1807 (sigle A des manuscrits de Platon), manuscrit de la «Collection philosophique » du $\mathrm{IX}^{\mathrm{e}}$ siècle, dérivant probablement d'un modèle provenant de la bibliothèque de l'école néoplatonicienne d'Alexandrie ${ }^{45}$. En amont du «fragment» sur les âges de l'Humanité, il faut donc se représenter un arrière-plan scolaire et exégétique, et le mélange d'érudition littéraire et philosophique qui caractérisait la culture des professeurs néoplatoniciens.

43. Lire par exemple: André-Jean Festugière, «L'ordre de lecture des dialogues de Platon aux Ve $/ \mathrm{VI}^{\mathrm{e}}$ siècles », Museum Helveticum, 26, 1969, p. 281-296, repris dans Études de philosophie grecque, Paris, Vrin, 1971, p. 535-550; et Leendert Gerrit Westerink, Jean Trouillard, Alain-Philippe Segonds, Prolégomènes à la Philosophie de Platon, Paris, Les Belles Lettres (CUF), 1990, p. LXVIILXXIII.

44. Voir Ph. Hoffmann, article « Damascius », DPhA, II, D3, p. 580. Ce point n'est pas très assuré.

45. Voir Leendert Gerrit Westerink, «Das Rätsel des untergründigen Neuplatonismus », dans Dieter Harlfinger, dir. ФІИОФРОNHMA. Festschrift für Martin Sicherl zum 75. Geburtstag. Von Textkritik bis Humanismusforschung (Studien zur Geschichte und Kultur des Altertums. Neue Folge 1, 4), Paderborn-Munich-VienneZurich, Schöningh, 1990, p. 105-123 ; Ph. Hoffmann, notice «Damascius », dans $D P h A$, II, p. 570 et 584-586, et «Les bibliothèques philosophiques d'après le témoignage de la littérature néoplatonicienne des $\mathrm{V}^{\mathrm{e}}$ et $\mathrm{VI}^{\mathrm{e}}$ siècles », dans Cristina D'Ancona, éd. The Libraries of the Neoplatonists. Proceedings of the Meeting of the European Science Foundation Network "Late Antiquity and Arabic Thought. Patterns in the Constitution of European Culture ». Strasbourg, March 12-14, 2004 (Philosophia Antiqua, 107), Leyde-Boston, Brill, 2007, p. 135-153 (p. 145-148). Un débat actuel sur l'existence même de la «Collection philosophique » (mise en question par Guglielmo Cavallo et Filippo Ronconi) me semble tranché par les travaux de Didier Marcotte, «Priscien de Lydie, la géographie et les origines néoplatoniciennes de la "Collection philosophique" », Journal des Savants, juilletdécembre 2014, p. 165-203; et « La "Collection philosophique" : historiographie et histoire des textes », Scriptorium, 68, 2014, p. 145-165. 
La doctrine de Damascius situe la $\pi$ o $\lambda \imath \varepsilon \varepsilon i ́ \alpha$ chrétienne au dernier niveau d'un processus de dégradation qui évoque les livres VIII et IX de la République et la description platonicienne de la corruption des $\pi \circ \lambda ı \tau \varepsilon i \alpha$, et qui est fondée sur l'idée d'une homologie de structure entre l'âme humaine et les régimes politiques déterminés par un certain état de l' $\tilde{\eta} \theta$ o $\zeta$ des citoyens : cette analogie parcourt la République, et Damascius, après Proclus ${ }^{46}$, réinterprète ici la théorie de Platon (notamment en Rép. IV et VIII-IX) selon laquelle il y a

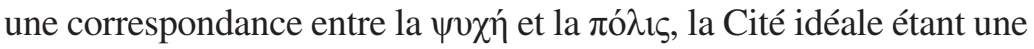
projection universelle de l'âme juste - dans le cadre d'une doctrine de la tripartition de l'âme, et des quatre vertus que sont la бopía,

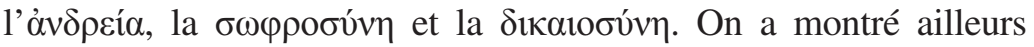
que l'anthropologie platonicienne de la République est le cadre conceptuel à travers lequel un Proclus appréhende le phénomène du christianisme, et l'état dégradé de l'âme chrétienne - ignorante, passionnelle et injuste ${ }^{47}$. Proclus lui-même s'inscrit dans la lignée des auteurs médio- et néoplatoniciens - Apulée $^{48}$, Alkinoos ${ }^{49}$, Saloustios $^{50}$ - qui avant lui ont proposé des résumés, ou des

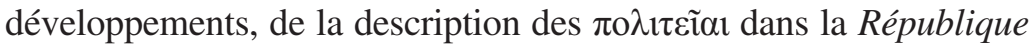
et de la doctrine du livre IV - objet de la VII ${ }^{\text {e }}$ Dissertation de l'In Rempublicam $^{51}$. Damascius s'inspire lui aussi des analyses de la République, mais pour penser une véritable histoire de l'Humanité, rompant ainsi avec une certaine tradition, mais tout en conservant la même perception «anthropologique» du présent que Proclus ${ }^{52}$. Le point de départ est probablement l'exposé du livre IV de la République (435 E 1-436 A 3), dans lequel Platon établit un lien de

46. Lire Proclus, In Rempublicam, I, p. 11, 5-14, 14 Kroll (Festugière, Proclus. Commentaire sur la République, I, Paris 1970, p. 27-30) : exposé du бколо́

47. Ph. Hoffmann, «Un grief anti-chrétien chez Proclus : l'ignorance en théologie », p. 163-164, 169-170, 196.

48. Apulée, De Platone et eius dogmate, livre II, 24-28, 255-263.

49. Alkinoos, Didaskalikos, XXXIV, H 188. 8-35 (éd. Whittaker, CUF, p. 69-70 et notes ad loc. p. 151-152).

50. Saloustios, Des dieux et du monde, X-XI (édition Rochefort, CUF, p. 15-16 et notes ad loc. p. 41-43; A. D. Nock, Sallustius. Concerning the Gods and the Universe, Cambridge 1926, p. lxxvi-lxxvii et 20-23).

51. Proclus, In Rempublicam, I, p. 206, 6-235, 21 Kroll (Festugière, Commentaire sur la République, II, Paris 1970, p. 13-39), sur le livre IV. - Voir notamment I, p. 208, 12-25 K. (Festugière II, p. 15) la description de l'activité

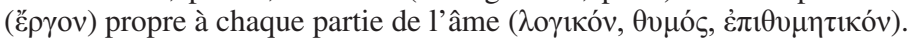

52. Cf. «Un grief antichrétien», p. 162 note 5. 
dérivation entre la psychologie et une géographie des peuples et des cultures. Au principe de la Raison et à l'amour de la connaissance ( $\tau$ ò $\varphi \imath \lambda o \mu \alpha \theta \dot{\varepsilon} \varsigma$ ) correspond la Grèce, centrée sur Athènes ; le principe

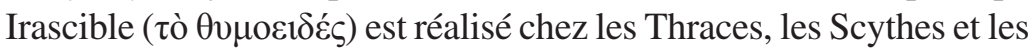
peuples du Nord, qui sont belliqueux ; et au principe Concupiscible,

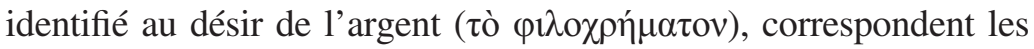
peuples de négociants, les Phéniciens et les Égyptiens :

$\mathrm{Ne}$ devons-nous pas, dis-je, reconnaître nécessairement que ces

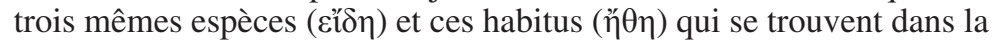
cité ( $\pi$ ó $1 \zeta$ ) existent aussi en chacun de nous ( $\dot{\varepsilon} v \dot{\varepsilon} \kappa \alpha ́ \sigma \tau \omega)$ ? Car ils ne sont certainement pas parvenus là provenant de je ne sais quelle autre

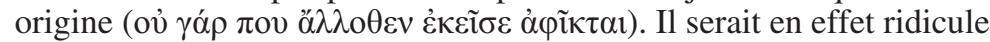

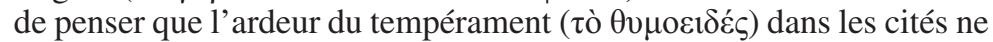
trouve pas son origine dans les individus particuliers ( $\dot{\varepsilon} \kappa \tau \tilde{\omega} v i \delta i \omega \tau \tilde{\omega} v)$, ceux-là mêmes qui possèdent cette réputation, à l'exemple de ceux qu'on trouve en Thrace et en Scythie, et presque dans toute la région du

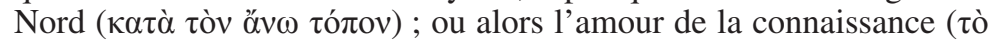
$\varphi \imath \lambda \mathrm{o} \mu \alpha \theta \dot{\varepsilon} \xi)$, qu'on pourrait tout à fait imputer à notre région ( $\tau$ òv $\pi \alpha \rho^{\prime}$

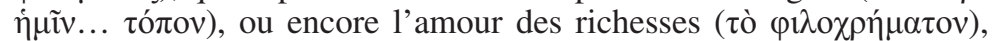
qu'on prétend trouver surtout chez les Phéniciens et chez les habitants de l’Égypte. ${ }^{53}$

Alors que Proclus reproduit assez fidèlement ${ }^{54}$ la géographie platonicienne de République IV, une nouveauté marquante s'observe dans le texte de la Vie d'Isidore : la tripartition de l'âme ne fonde plus une géographie, mais une histoire, qui porte incontestablement une marque hésiodique - le lecteur est immédiatement renvoyé au mythe des races, suggéré par la mention de la « race d'or », $\chi \rho v \sigma \eta \tilde{~}$ $\gamma \varepsilon v \varepsilon \alpha^{55}$. Mais comment les trois âges de l'humanité s'articulentils aux cinq races d'Hésiode? Damascius pourrait se souvenir de l'usage, fait par Platon lui-même, dans la République, du mythe des races pour décrire la tripartition sociale. Au livre III de la République (415 A-C), dans le contexte du $\mu \tilde{\theta} \theta$ os sur la fondation de la différenciation sociale, Platon articule le mythe de l'autochtonie et le mythe des races, lequel est remodelé, les races hésiodiques

53. Traduction de Georges Leroux, GF, Paris 2002, p. 241-242. 27).

54. Proclus, In Rempublicam, I, p. 221, 12-222, 3 Kroll (Festugière II, p. 26-

55. Hésiode, Les travaux et les jours, v. 109-126. Une mention de la race d'or se lit chez Platon, République, V, 468 E 5-6 (à propos des guerriers valeureux

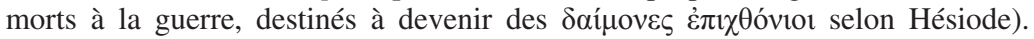
D'autres passages de la République font usage du mythe hésiodique des races, comme nous allons le voir immédiatement. 
étant réorganisées selon la tripartition platonicienne ${ }^{56}$. Mais l'on peut songer aussi au livre VIII, en 546 C-547 C, dans le contexte de l'analyse de la dégradation des constitutions (Platon explique alors que l'inculture de rejetons mal nés conduira à confondre les « races » d'Hésiode, qui correspondent à la structure sociale, et

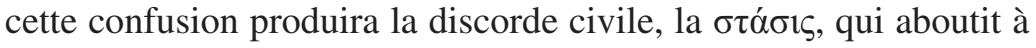
l'établissement de la timocratie, intermédiaire entre l'aristocratie et l'oligarchie ${ }^{57}$ ).

En fait, dans le texte de Damascius, seul le premier âge de l'Humanité, celui qui correspond à la race d'or, a une couleur hésiodique. Le deuxième âge présente des traits qui peuvent

56. « Vous qui faites partie de la cité, vous êtes tous frères, leur dirons-nous

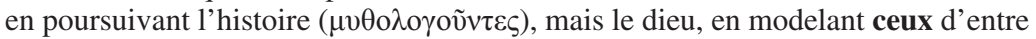

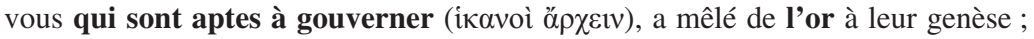

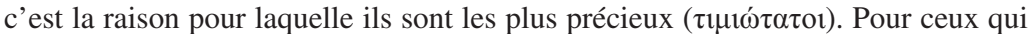

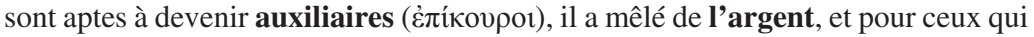

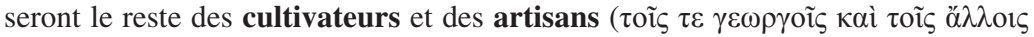
$\delta \eta \mu 10 v \rho \gamma o i ̃ s)$, il a mêlé du fer et du bronze. (...) Si [les] rejetons [des gouvernants]

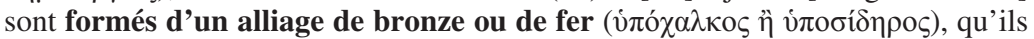
n'aient aucune forme de pitié à leur égard et qu'ils les assignent aux tâches des artisans et des cultivateurs, en respectant ce qui convient à leur nature; si par ailleurs surgissent dans leur descendance quelques rejetons alliant l'or et l'argent

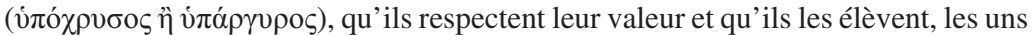
à la tâche de gardiens ( tenant compte de ce que l'oracle dit que la cité périra si son gardien est de fer

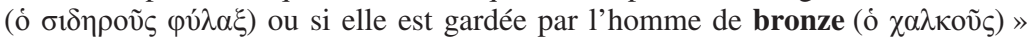
[traduction Georges Leroux, GF, Paris 2002, p. 210]. - Luc Brisson me fait observer à ce propos que cette tripartition des « races » chez Platon est fondée sur la tripartition fonctionnelle qui a un spectre beaucoup large, comme il le montre dans son article «La tri-fonctionnalité indo-européenne chez Platon», dans Philosophie comparée. Grèce, Inde, Chine (Annales de l'Institut de Philosophie de l'Université de Bruxelles), coordination scientifique Joachim Lacrosse, Paris, Vrin, 2005, p. 121-142.

57. «Lorsque la discorde surgit, (...) alors les deux ensembles de races

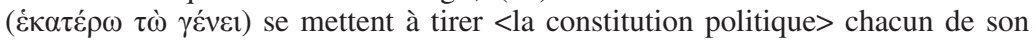
côté : les races de fer et de bronze tendent vers la recherche de la richesse, la

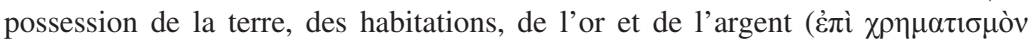

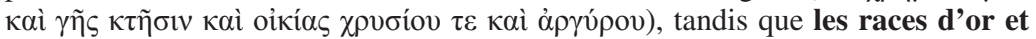
d'argent, qui ne souffrent pas de la pauvreté compte tenu du fait qu'elles sont

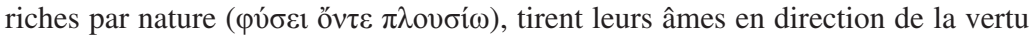

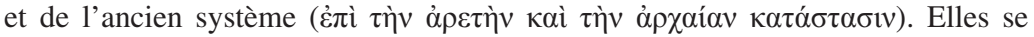
dressent violemment les unes contre les autres, elles entrent en conflit, mais elles finissent par convenir de mettre en commun la terre et les habitations, pour les répartir et les donner en propriété privée [...]. Eh bien ! dis-je, cette constitution politique n'occupera-t-elle pas la position intermédiaire entre l'aristocratie et l'oligarchie ? (547 B 2-C 7, traduction Georges Leroux, retouchée, GF, Paris 2002, p. 407). Cf. le commentaire de Proclus, cité à la note suivante. 
évoquer la race de bronze ou celle des héros ${ }^{58}$. L'âge présent, lui, est décrit comme l'empire de l'غ̇ंı $\theta v \mu \mu^{\prime} \alpha$, et ne relève plus du schème hésiodique : seule sa dimension complètement négative permettrait de faire un rapprochement - superficiel - avec la race de fer.

\section{UN AUTRE SCHÈME DE PENSÉE : LE MÉLANGE AVEC PRÉDOMINANCE}

Cet usage platonicien du mythe hésiodique des races avait déjà été commenté par Procluss ${ }^{59}$. À cette référence Damascius mêle, pour décrire les trois âges de l'humanité, un autre schème extrêmement puissant dans la pensée grecque, et en particulier dans toute la métaphysique néoplatonicienne : le schème du mélange avec prédominance. Les trois états du «fragment» de Damascius expliquent de façon concordante que chacun des trois âges

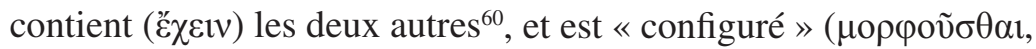
$\delta 1 \alpha \mu о \rho \varphi о \tilde{\sigma} \sigma \alpha \mathrm{l})$ - c'est-à-dire déterminé dans sa forme -, et aussi

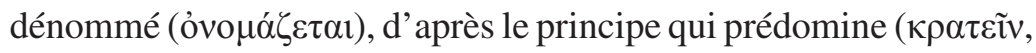
$\dot{\varepsilon} \pi$ - minoritaire pourrait-on dire - des deux autres. Le schème de la

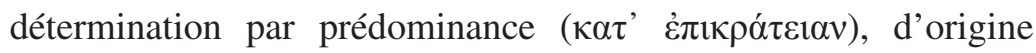
anaxagoréenne ${ }^{62}$, est un outil très présent dans le néoplatonisme ${ }^{63}$,

58. Voir supra, notes 18 et 29.

59. Proclus, In Rempublicam, II, p. 75, 12-78, 11 Kroll, spéc. p. 77, 19-78, 11 sur l'interprétation platonicienne du mythe des races (traduction A.-J. Festugière, Proclus. Commentaire sur la République, II, Paris 1970, p. 186-188).

60. Proclus, déjà, dans In Rempublicam, I, p. 230, 14-18 sqq. K. (Festugière, II, p. 35-36), explique que « les façons de vivre de l'âme ne sont pas pures de tout

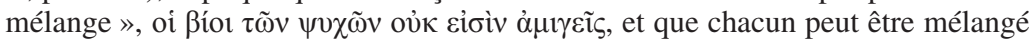
avec les autres. Mais sa perspective est bien différente de celle de Damascius.

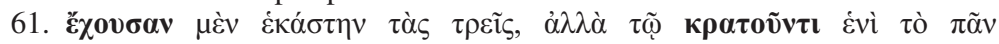

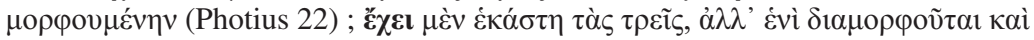

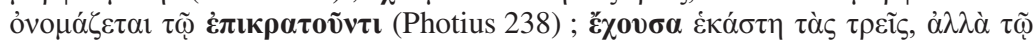

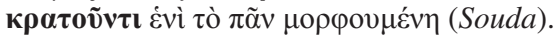

62. Cf. Aristote, Physique, I, 4, 187 b 1-7.

63. Voir P. Hadot, « Être, Vie, Pensée chez Plotin et avant Plotin », dans Les sources de Plotin (Entretiens sur l'Antiquité Classique, Fondation Hardt, t. V. Vandœuvres-Genève 21-29 août 1957), Genève 1960, p. 107-157 (124-130) ; repris dans Plotin, Porphyre. Études néoplatoniciennes, Paris, Les Belles Lettres, 1999, p. 127-181 (142-147) ; id., Porphyre et Victorinus, I, Paris 1968, p. 239-244 ; Ph. Hoffmann, «Sur quelques aspects de la polémique de Simplicius contre Jean Philopon: de l'invective à la réaffirmation de la transcendance du 
peut-être admis déjà par Numénius ${ }^{64}$, et le principe énoncé dans la Sentence 10 de Porphyre ${ }^{65}$ est utilisé notamment par Proclus pour décrire la structure de la triade de l'Être, de la Vie et de la Pensée dans la Proposition 103 des Éléments de Théologie ${ }^{66}$ : il est ici appliqué à la description de la structure mixte de chacun des âges de l'Humanité. Ainsi s'explique en particulier que dans l'âge actuel de corruption soient encore présents des philosophes, serviteurs de la Raison et contempteurs de l'injustice.

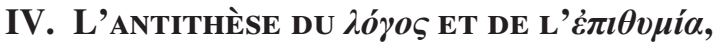 ET « LA VIE SOUS LE RÈGNE DE CRONOS »}

Bien qu'il expose la succession de trois âges de l'Humanité, et qu'il évoque aussi l'époque historique de la Grèce ancienne et de la Rome païenne comme un temps de $\varphi \imath \lambda o \tau \iota \mu$ í, le texte est dominé par une

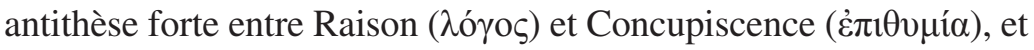

Ciel », dans Ilsetraut Hadot, éd., Simplicius : sa vie, son æeuvre, sa survie (Actes du Colloque international «Simplicius ». Paris, Fondation Hugot du Collège de France, 28 septembre- $1^{\text {er }}$ octobre 1985) [Peripatoi, Bd 15], Berlin-New York, De Gruyter, 1987, p. 183-221 (p. 214-215) ; et l'étude fondamentale de Jocelyn Groisard, Mixis. Le problème du mélange dans la philosophie grecque d'Aristote à Simplicius, Paris, Les Belles Lettres («Anagôgê », 9), 2016, spéc. p. 227 sqq. : Le mélange en métaphysique néoplatonicienne.

64. Selon un passage du De anima de Jamblique, où le principe est ainsi formulé :

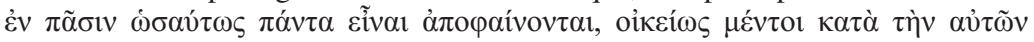

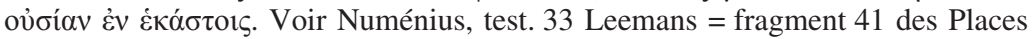
(CUF, Paris 1973, p. 90), cité par Stobée, I, 49, 32 ; p. 365, 5-21 (voir 365, 12-14) Wachsmuth $=$ Jamblique, De anima, 6 dans John F. Finamore et John M. Dillon, Iamblichus «De anima». Text, Translation and Commentary (Philosophia Antiqua, 92), Leyde-Boston-Cologne, Brill, 2002, p. 30-31 et p. 89-90. Il faut se reporter à la traduction annotée d'A.-J. Festugière, La Révélation d'Hermès Trismégiste, nouvelle édition revue et augmentée, Paris, Les Belles Lettres, 2014, p. 1284.

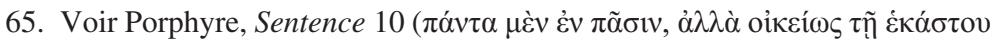
ov̉oía), et les commentaires ad loc., dans Luc Brisson et alii, Porphyre. Sentences (coll. "Histoire des doctrines de l'Antiquité classique », XXXIII), Paris, Vrin, 2005, t. I, p. 310-311, et t. II, p. 400-403. - Syrianus, In Metaphysica (M 1), p. 81, 31-82, 2 Kroll (CAG VI, 1) attribue l'origine de ce principe (... E⿱亠凶禸v $\alpha$ l $\delta \dot{\varepsilon} \kappa \alpha \theta$ '

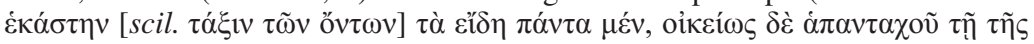

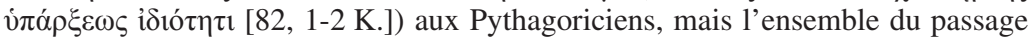
est d'une indéniable couleur néoplatonicienne.

66. Voir Eric R. Dodds, Proclus. The Elements of Theology, Oxford, Clarendon Press, $1933\left(1963^{2}\right)$, Prop. 103, p. 92, 13-29, avec traduction p. 93 et commentaire p. 254 (avec un renvoi à Théol. Plat. IV, 1-3). 
la disqualification du présent de l'Empire chrétien est conduite non seulement par la rhétorique de l'invective et un style accumulant les termes négatifs, mais par l'effet même de contraste entre ce présent et ce que serait (ou ce qu'a été) une $\pi$ o $\lambda \imath \tau \varepsilon i ́ \alpha$ conforme aux normes de l'Intellect, réalisant la vie «cronienne ». L'évocation du premier âge mérite, pour cette raison, une attention toute particulière, parce qu'elle relie avec précision cette philosophie de l'Histoire à la théologie néoplatonicienne. Comparé à la $\pi 0 \lambda \imath \tau \varepsilon i ́ \alpha$ parfaite, régie par la Justice, l'Empire byzantin est décrit comme une inversion de la $\sigma \omega \varphi \rho о \sigma u ́ v \eta$, et est rejeté dans les bas-fonds de la $\gamma \varepsilon ́ v \varepsilon \sigma 1 \zeta$.

Dans la première $\pi 0 \lambda \imath \tau \varepsilon i ́ \alpha$ prédomine donc la Raison, et cet âge s'identifie à «la vie sous le règne de Cronos » (ó Ėंì Kpóvov $\beta i ́ o s)$, ce qui correspond à la fois à l'âge d'or hésiodique, et à la

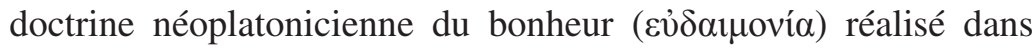
la vie de l'Intellect divin - antithèse du «malheur des temps » déploré à travers l'évocation de la vie « des hommes qui à présent

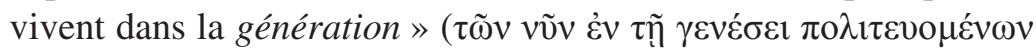
$\dot{\alpha} v \theta \rho \omega ́ \pi \omega v)^{67}$. Le texte de Damascius s'inscrit dans une longue tradition de réflexion néoplatonicienne sur l'Intellect (divin), symbolisé par la figure de Cronos, et l'allusion s'imposait au lecteur averti des doctrines néoplatoniciennes. Cela est prouvé par la scholie de Proclus au vers 111 des Travaux d'Hésiode, oî $\mu \varepsilon \grave{v}$

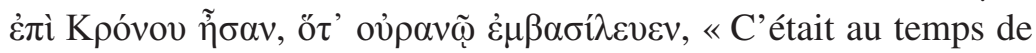
Cronos, quand il régnait encore au ciel » (traduction Paul Mazon). Proclus établit explicitement une liaison entre « la vie sous le règne

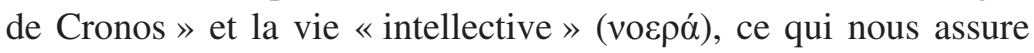
qu'une telle association ne force pas le texte de Damascius et que nous avons affaire à une allusion sans aucun doute intentionnelle, et perçue comme telle par les lecteurs anciens :

CEUX DE L'ÉPOQUE DE CRONOS : Que les hommes de la race d'or menaient une vie pure, immatérielle, exempte de passions, et que cette vie est désignée par l'or, selon l'explication donnée aussi par Platon $^{68}$, c'est évident. L'or ne peut être en effet atteint par la rouille

67. Voir infra, p. 765-768 et notes 105-108, la discussion du texte.

68. Platon, Cratyle, 398 A 4-6, où Socrate explique le mythe des races et affirme qu'Hésiode "par "race d'or", entend non pas "née de l'or", mais "bonne et belle". Et la preuve [...] c'est qu'il nous appelle nous-mêmes "race de fer" »

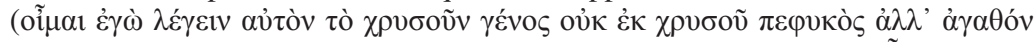

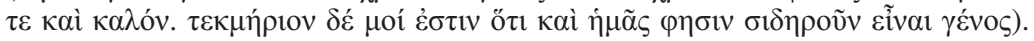
- Par ailleurs, pour le thème de l'âge d'or, identifié à l'âge de Cronos, le mythe 
et la décomposition ${ }^{69}$, et pour cette raison il représente ${ }^{70}$ l'absence de $^{\text {'a }}$ passions. Mais quel était le type de vie de tels hommes sous le règne de Cronos, nous pouvons le comprendre en réfléchissant que Cronos est

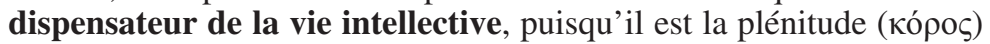

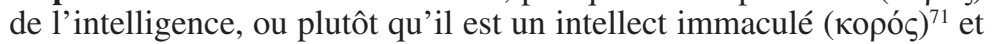

du Politique (voir infra, note 73) est la médiation entre Hésiode et les auteurs néoplatoniciens.

69. Cf. un texte très proche en In Rempublicam, II, p. 75, 15-18 Kroll : $\tau$ ò $\mu$ غ̀v

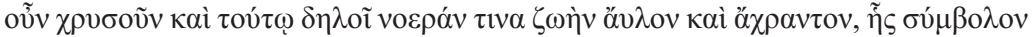

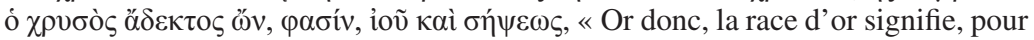
Hésiode aussi, une certaine vie intellective immatérielle et pure, dont le symbole est l'or qui, comme on dit, n'est susceptible ni de rouille ni de putréfaction » (traduction A.-J. Festugière, Proclus. Commentaire sur la République, II, Paris 1970, p. 186). Le contexte est un développement comparant, à propos de République, VIII, 546 E $1 s q q$. , le mythe des races dans la version orphique, la version hésiodique et l'interprétation donnée par Platon (In Remp., II, p. 74, 26-78, 11 Kroll = Festugière, II, p. 185-188). Selon Proclus (In Remp., II, p. 74, 26-75, $12 \mathrm{~K}$., cf. fr. $140 \mathrm{Kern}=159 \mathrm{~F}$ Bernabé), Orphée distingue entre la race d'or, créée par Phanès, la race d'argent, sur laquelle a régné Kronos, et la race « Titanique »

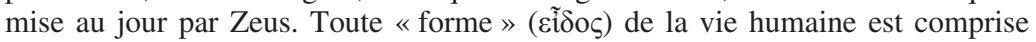

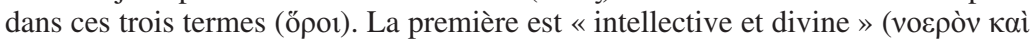

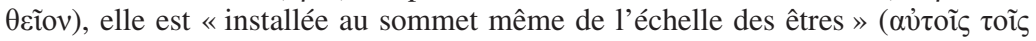

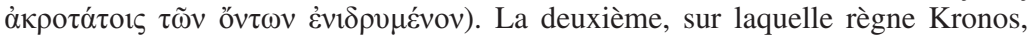
« est convertie vers elle-même, s'intellige elle-même et se contente de ce genre

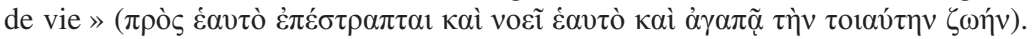
La troisième, celle de Zeus, "regarde vers les êtres inférieurs, et c'est avec eux,

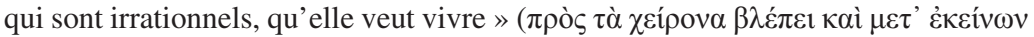

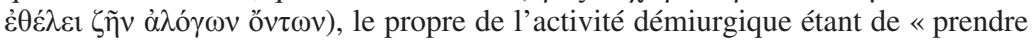

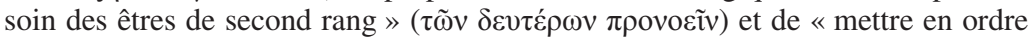

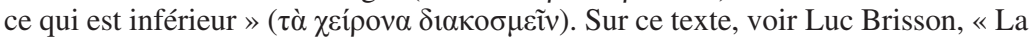
figure du Kronos orphique chez Proclus », cité infra (note 86), aux pages 448-449.

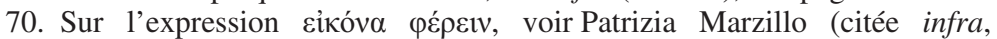
note 72), p. 317 n. 4 ( $a d$ sch. XLVI).

71. Les éditeurs (Pertusi et Marzillo) distinguent entre deux formes, diversement

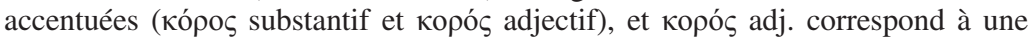
entrée du LSJ (voir l'éd. augmentée de 1996, p. 982), qui s'appuie sur les textes que nous étudions (Proclus, Théol. Plat., V, 3 (p. ?) ; id., In Opera et Dies, v. 111 ; Etymologicum Magnum, 540, 4-8 (reprise partielle de la scholie de Proclus sur Hésiode, l'édition Gaisford présentant [540,5] les deux accentuations kópo et

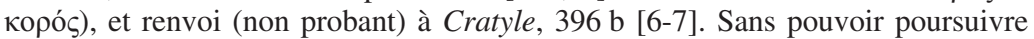
plus avant cette recherche, je remarque que l'édition de M. van der Valk, Eustathii Commentarii ad Homeri Iliadem Pertinentes. Vol. I (ad libros A- $\Delta$ ), Leyde, Brill,

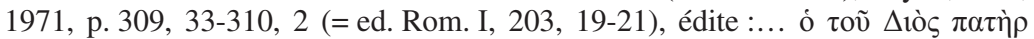

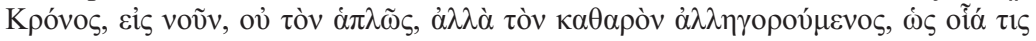
кopò $\varsigma$ voṽ $\kappa \tau \lambda$. Cf. une autre mention de l'étymologie de Kronos chez Eustathe (éd. van der Valk, vol. III ([ad libros K-П], Leyde 1979, p. 721, 6-7 (= ed. Rom. II,

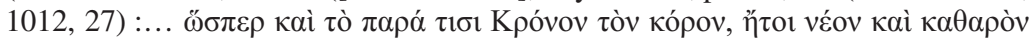

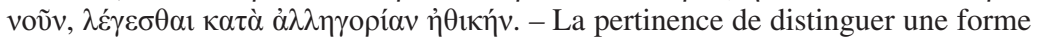
d'adjectif pour comprendre le texte de Platon a été mise en doute par Marguerite Harl, «Recherches sur l'origénisme d'Origène: la "satiété" (кópos) de la 
pur (le [mot] « immaculé », korón, signifie en effet «pur », katharon). Donc tous les hommes qui vivent de la vie intellective (noerôs) ont une constitution (politeia) «cronienne» : et pour cette raison l'on dit que Cronos règne sur eux, tout comme Zeus règne sur ceux qui vivent selon des [principes] politiques (politikôs) en suivant la meilleure constitution (politeia), celle qui institue la communauté des biens. Il ne faut donc pas penser que c'est la souveraineté des dieux qui subit un changement, mais que, lorsque les âmes changent de [type de] vie, il [scil. Hésiode] établit un autre dieu comme leur roi ; et [il faut concevoir que] c'est le mythe qui opère un transfert en attribuant ce changement non pas à nous [les hommes], mais aux rois. ${ }^{72}$

\section{Excursus sur la figure de Cronos DANS LA TRADITION NÉOPLATONICIENNE}

Sans pouvoir entreprendre ici une histoire approfondie des usages philosophiques de la figure de Cronos, qui excéderait les limites de cette étude, il convient de rappeler l'importance de la spéculation plotinienne, puis de signaler les principaux textes de Proclus qui, dans la Théologie Platonicienne et le commentaire sur le Cratyle, a situé le dieu Cronos au «sommet» de l'ordre des Intellectifs - doctrine qui pour l'essentiel est reprise par Damascius. La formule proverbiale, utilisée par Platon dans le Politique ${ }^{73}$ pour décrire un

contemplation comme motif de la chute des âmes ", dans Studia Patristica, VIII (= Texte und Untersuchungen zur Geschichte der altchristlichen Literatur, t. 93), Berlin, Akademie-Verlag, 1966, p. 373-405 (voir note 4, p. 400-401).

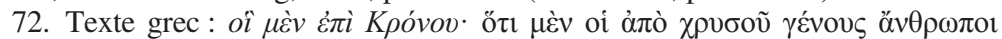

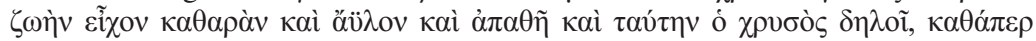

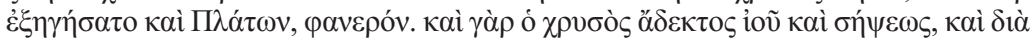

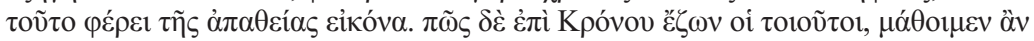

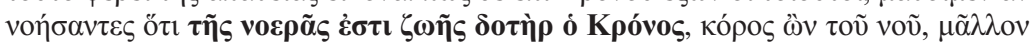

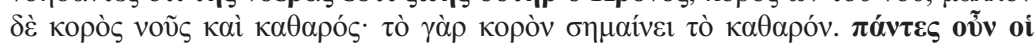

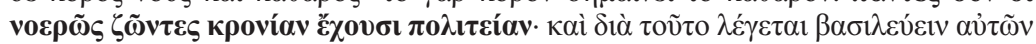

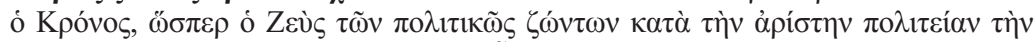

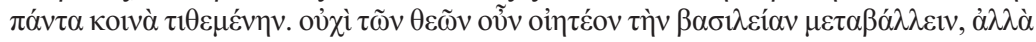

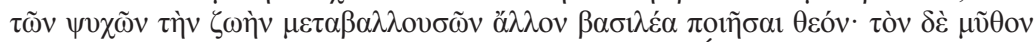

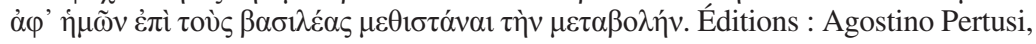
Scholia vetera in Hesiodi Opera et Dies (Pubblicazioni dell'Università Cattolica del s. Cuore. Nuova Serie. Volume LIII), Milan, Società editrice «Vita e Pensiero », 1955, p. 50, 2-17 ; Patrizia Marzillo, Der Kommentar des Proklos zu Hesiods «Werken und Tagen». Edition, Übersetzung und Erläuterung der Fragmente (Classica Monacensia, 33), Tübingen, Narr Verlag, 2010, scholie LXX, p. 52-53.

73. Platon, Politique : le règne de Cronos opposé à celui de Zeus, $269 \mathrm{~A} 7$ sqq, 269 C sqq, spécialement 271 C 4-5 (

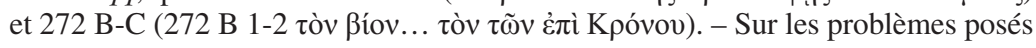


état du monde antérieur à l'état présent (qui est le règne de Zeus), apparaît chez Plotin qui l'emploie pour décrire la vie de l'Intellect divin $^{74}$, dans le contexte d'un jeu étymologique où l'analyse du

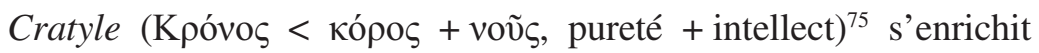

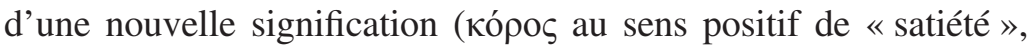
«plénitude » $)^{76}$. En même temps, Plotin superpose - à travers un

par le mythe du Politique, et le rapport de Platon à Hésiode, lire par exemple, au milieu d'une très abondante bibliographie: Mauro Tulli, «Età di Crono e ricerca sulla natura nel "Politico" di Platone», dans Studi Classici e Orientali, 40, 1991, p. 97-115 ; Luc Brisson, "Interprétation du mythe du Politique », dans Christopher Rowe, éd. Reading the "Statesman». Proceedings of the III Symposium Platonicum («International Plato Studies », 4), Sankt Augustin, 1995, p. 349-363, repris dans L. Brisson, éd. Lectures de Platon, Paris, 2000, p. 169-205 ; id., « Le mythe du Politique à la lumière des Lois : un argument supplémentaire en faveur des trois phases », Polis : The Journal for Ancient Greek Political Thought, 31, 1, 2014, p. 122-150 ; et aussi Dimitri El Murr, « Hesiod, Plato and the Golden Age: Hesiodic Motifs in the myth of the Politicus », dans G. R. Boys-Stones et J. H. Haubold, dir. Plato and Hesiod, Oxford-New York, Oxford University Press, 2010, p. 276-297 ; et, dans le même volume, Christopher Rowe, « On grey-haired babies : Plato, Hesiod and visions of the past (and future)», p. 298-316. - Mais cette question ne concerne pas directement notre recherche sur Damascius.

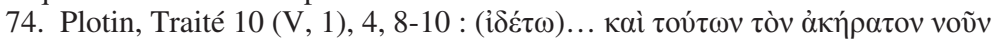

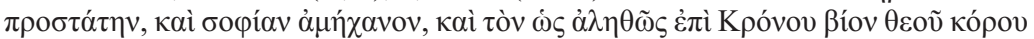

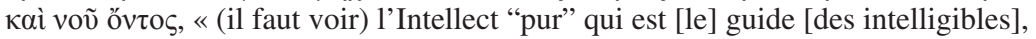
la sagesse prodigieuse et la vie véritable sous le règne de Cronos, le dieu qui est "satiété" et Intellect » (traduction Francesco Fronterotta, dans Plotin. Traités 7-21 [GF 1164], Paris 2003, p. 158, cf. p. 182 note 63). Voir aussi le même Traité 10 (V, 1), 7, 27-38, et le commentaire de Michael Atkinson, Plotinus : Ennead V. 1. On the three principal hypostases. A Commentary with Translation by M. A., Oxford University Press, 1983, p. 78-79, 175-180.

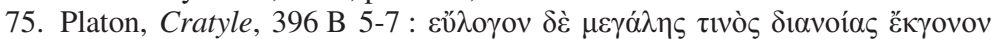

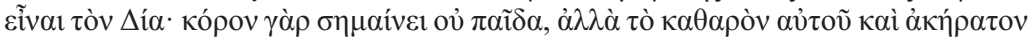

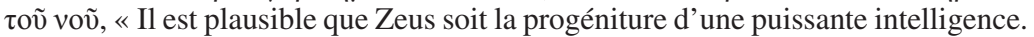
"Propreté", voilà le sens du nom de Cronos : non pas en effet "jeune garçon", mais "ce qu'il y a de pur", de "non mélangé" dans son intellect » (d'après Léon Robin, Platon. Euvres complètes, I, Paris, Gallimard, 1977 (1950), p. 630, avec des modifications). Cf. Hugo Koning, «Plato's Hesiod : not Plato's alone », dans G. R. Boys-Stones et J. H. Haubold, dir. Plato and Hesiod (cité supra, note 73), p. 104-105 (sur les étymologies de Zeus, Cronos et Ouranos, et le rapport entre généalogie et étymologie). - Une allusion à l'étymologie du Cratyle se lit déjà chez Plutarque, De facie, 942 A.

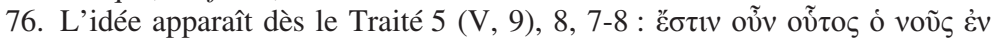

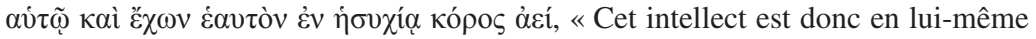
et, puisqu'il se possède lui-même dans la tranquillité, il est éternellement rassasié » (traduction Francesco Fronterotta, Plotin. Traités 1-6 [GF 1155], Paris 2002, p. 207, $c f$. n. 67 p. 221). L'étymologie est d'origine stoïcienne et a un parallèle latin («Saturnus autem est appellatus quod saturaretur annis », Cicéron, De natura deorum, II, 25, 64). Elle apparaît aussi chez Augustin, qui adapte l'étymologie du traité $10(\mathrm{~V}, 1)$, ch. 4 et 7 de Plotin, dans le De consensu evangelistarum, I, 23, 
filtre platonicien - les deux références hésiodiques : le Cronos de la Théogonie, le dieu qui dévore ses propres enfants dès leur naissance, illustre la thèse de l'intériorité des Intelligibles à l'Intellect divin, il est le second un qui produit en lui la totalité des Formes-intellects et les retient en lui, - tandis que le Cronos des Travaux d'Hésiode, sous le règne duquel vit la race d' ${ }^{\prime}{ }^{77}$, exprime la thèse du bonheur parfait qui est celui de la tranquille contemplation des Formes intelligibles

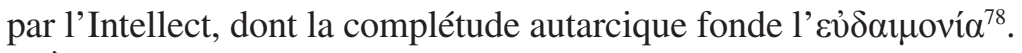

À plusieurs reprises dans son œuvre, Plotin procède ainsi à une réélaboration philosophique du mythe d'Ouranos, Cronos et Zeus ${ }^{79}$ - déjà reformulé par Platon dans le Cratyle ${ }^{80}$. Le récit hésiodique narrant la mutilation d'Ouranos par son fils Cronos, l'acte par lequel celui-ci dévore ses propres enfants et la révolte de Zeus qui vainc enfin son père «par ses ruses et sa force $»^{81}$ est pour Plotin,

34-35 (éd. Weihrich, CSEL 43, p. 33, 4-6 et surtout 12-17) : Saturnus/saturari, Saturnus $=$ Cronos $=$ «satiété de l'intelligence $»($ car $《$ satietas $»=\langle\operatorname{coros} »)$ = satur nûs, «intelligence rassasiée ». Voir Arthur Stanley Pease, éd. M. Tulli Ciceronis De natura deorum Libri secundus et tertius, Cambridge Ma., Harvard University Press, 1958, p. 709-712, où les notes ( $a d$ II, 25, 64) rassemblent un dossier considérable sur les noms et le mythe de Cronos-Saturne ; Pierre Courcelle, Les lettres grecques en Occident, de Macrobe à Cassiodore, Paris, De Boccard, 1948, p. 162-163 (Augustin et Plotin); et Jean Pépin, Mythe et allégorie, cité infra (note 84), p. 126, p. 204 et n. 116 (traduit le texte d'Augustin, qui ici «se propose de traduire en latin la substance de l'Ennéade V, 1, 4 »). - Une histoire du mot et de la notion de кópos a été brossée par Marguerite Harl, «Recherches sur l'origénisme d'Origène : la "satiété" (кópos) de la contemplation comme motif de la chute des âmes », cité supra n. 71 (voir p. 400-401 sur Platon, Cratyle, 396 B, et sur Plotin, et un classement des significations de kópos, p. 405 n. 1).

77. Hésiode, Les travaux et les jours, v. 109-126. - Sur le thème multiforme de l'âge d'or (célébré par Ovide, Métamorphoses, I, 89-112), lire par exemple l'histoire générale rassemblée par Bodo Gatz, Weltalter, goldene Zeit und sinnverwandte Vorstellungen (Spudasmata, XVI), Hildesheim, Olms, 1967 (spéc. p. 114-128, Das Leben unter Kronos-Saturn), et les perspectives philosophiques proposées par Pierre Hadot dans Le Voile d'Isis. Essai sur l'histoire de l'idée de Nature, Paris, Gallimard, 2004, p. 154-157, 215-216.

78. Et tel est aussi, pour Plotin, le bonheur de la part, demeurée en haut, de chacune des âmes. - Sur la conception néoplatonicienne du bonheur, lire principalement Plotin, Traité 46 (I, 4), et Marinus, Proclus ou Sur le bonheur, cité supra, note 7.

79. Plotin, Traité 10 (V, 1), 4, 8-10 et 7, 27-38 ; Traité 30 (III, 8), 11, 26-42 ; Traité $31(\mathrm{~V}, 8), 12,3-26$ et 13, 1-11 ; Traité 32 (V, 5), 3, 21-24 ; Traité 50 (III, 5), $2,19-21$ et 32-35, à propos de l'Âme-Aphrodite Ouranienne. Cf. aussi Traité 38 (VI, 7), 15, 18-20 et 35, 30-32.

80. Platon, Cratyle, 396 B-C.

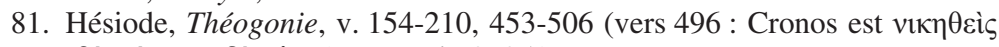

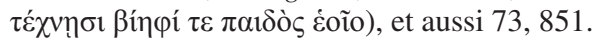


qui en réécrit une version apaisée et épurée ${ }^{82}$, un mythe hellène, opposable aux complexes mythologies gnostiques, étrangères selon lui à l'hellénisme, et c'est aussi un mythe d'une grande simplicité, antithèse des multiples généalogies gnostiques. Les trois dieux constituant une lignée - Ouranos, Cronos, Zeus - figurent pour Plotin les trois niveaux principiels, l'Un, l'Intellect et l'Âme. Les niveaux principiels sont au nombre de trois, et les intermédiaires entre le premier Principe et nous ne sont pas nombreux : ov̉ $\delta \grave{\varepsilon}$ $\pi \mathrm{o} \lambda \lambda \grave{\alpha} \tau \grave{\alpha} \mu \varepsilon \tau \alpha \xi \xi^{83}$. Le mythe d'Hésiode résume ainsi les deux thèses fondamentales de Plotin - les trois niveaux principiels de la Réalité et l'intériorité des Formes intelligibles à la Pensée divine ${ }^{84}$.

82. Il faut rappeler les fortes réserves de Platon, République, II, 377 E-378 A, à l'égard de ce mythe qui ne convient pas aux jeunes. Mais c'est Platon lui-même qui, dans le Cratyle, 396 A-C, pose les bases de l'usage philosophique du mythe d'Ouranos, Cronos et Zeus.

83. Plotin, Traité $10(\mathrm{~V}, 1), 3,4$.

84. Les études fondamentales sont celles de Jean Pépin, « Plotin et les Mythes », Revue philosophique de Louvain, 53, 1955, p. 5-27, repris dans Mythe et allégorie. Les origines grecques et les contestations judéo-chrétiennes, Paris, Aubier, 1958, p. 190-209, spéc. p. 203-206 (2édition, Études Augustiniennes, 1976) ; et Pierre Hadot, " Ouranos, Kronos and Zeus in Plotinus' Treatise Against the Gnostics », dans H.J. Blumenthal et R.A. Markus (eds.), Neoplatonism and Early Christian Thought. Essays in Honour of A.H. Armstrong, Aldershot, Variorum Publications, Londres 1981, p. 124-137, et "Images mythiques et thèmes mystiques dans un passage de Plotin (V. 8. 10-13) », dans Néoplatonisme. Mélanges offerts à Jean Trouillard, Les Cahiers de Fontenay ( ${ }^{\circ}$ 19-22), ENS de Fontenay-aux-Roses, mars 1981, p. 205-214 (cf. id., « Plotin et les Gnostiques », dans Plotin, Porphyre. Études néoplatoniciennes, Paris, Les Belles Lettres, 1999, p. 222-223) ; Plotin. Traité 38 (VI, 7), Paris, Éditions du Cerf, 1988, p. 39-41, 127, 175, 263-265, 269, 343-344 ; Plotin. Traité 50 (III, 5), Paris, Éditions du Cerf, 1990, p. 48-50, 74, 110-112, 170-179. Lire aussi Robert Lamberton, Homer the Theologian. Neoplatonist Allegorical Reading and the Growth of the Epic Tradition, BerkeleyLos Angeles-Londres, University of California Press, (1986 $\left.{ }^{1}\right)$ 1989, p. 104-106 ; Loraine Oliveira, «A genealogia mítica : Urano, Cronos e Zeus em Plotino », dans Revista de Estudos Filosóficos e Históricos da Antiguidade, 25, 2008/2009, p. 109-133, et Plotino escultor de mitos, São Paulo, 2013, p. 199-226 ; Luciana Gabriela Soares Santoprete, «Le mythe d'Ouranos, Kronos et Zeus comme argument antignostique chez Plotin », dans Anna Van den Kerchove et Luciana Gabriela Soares Santoprete, éd. Gnose et Manichéisme. Entre les oasis d'Égypte et la Route de la Soie. Hommage à Jean-Daniel Dubois (coll. Bibliothèque de l'École des Hautes Études. Sciences religieuses. $176=$ Série « Histoire et prosopographie de la Section des Sciences Religieuses », 13), Paris 2016, p. 829-858 (où l'on trouvera une très riche bibliographie, et le dossier des textes gnostiques, notamment valentiniens, auxquels Plotin s'oppose), et « New Perspectives on the Structure of Plotinus' Treatise 32 (V 5) and his Anti-Gnostic Polemic », dans Helmut Seng, Luciana Gabriela Soares Santoprete et Chiara O. Tommasi, dir. Formen und Nebenformen des Platonismus in der Spätantike, Heidelberg, Universitätsverlag 
Un texte particulièrement saisissant se lit dans le Traité $31(\mathrm{~V}, 8)$ Sur la beauté intelligible, qui est une partie du grand traité Contre les Gnostiques. Les chapitres 12 et 13 représentent l'achèvement d'une longue exégèse du cortège de Zeus dans le Phèdre: le

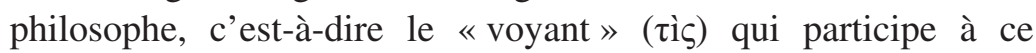
cortège, révèle la Beauté du Monde intelligible (=Cronos), fils d'Ouranos et père de Zeus, en un véritable évangile philosophique païen. Les aspects terribles du mythe sont effacés par l'allégorie, qui fonctionne chez Plotin comme mode d'expression voilée, et dont le style apocalyptique répond probablement, et s'oppose, à des formes littéraires familières aux gnostiques ${ }^{85}$.

Après Plotin, la figure de Cronos, et la triade des dieux Ouranos, Cronos et Zeus, continuent de jouer un rôle structurant dans la doctrine néoplatonicienne, moyennant des réélaborations, et une modification de leur situation dans l'ordre hiérarchique du Réel, la référence hésiodique se trouvant souvent appréhendée à travers le filtre de l'interprétation orphique du mythe. Dans le livre V de la Théologie platonicienne ${ }^{86}$ Proclus reprend l'interprétation de

Winter, 2016, p. 109-162 (p. 120, 122-123). Le dossier est aussi clairement présenté (mais sans prendre suffisamment en compte la dimension antignostique) dans l'article d'Izabela Jurasz, « L'Intellect-Kronos chez Plotin. La place du mythe dans la noétique plotinienne », dans la revue en ligne Methodos. Savoirs et textes, 16 | 2016 [La notion d'Intelligence (nous-noein) dans la Grèce antique], 28 pages (mis en ligne le 19 janvier 2016, consulté le 7 août 2017 ; accessible à l'adresse : URL : https://methodos.revues.org/4401 ; DOI : 10.4000/methodos.4401). Cette étude très bien informée met en évidence le fait que le rapport de Plotin à Hésiode n'est pas direct, et passe par la médiation de Platon (notamment le Cratyle). Giulia Guidara a eu la gentillesse de me faire lire son bel article «Il mito di Kronos in Plotino : la teoria dell'Intelletto fra modello artigianale e modello biologico », à paraître dans Studia Graeco-Arabica, où elle montre notamment comment la figure de Cronos permet à Plotin de donner la préférence à un modèle «biologique » (l'Intellect est père des Formes qu'il retient en lui) sur le modèle « artisanal » du Démiurge, en liaison avec la théorie de la connaissance dans l'Intellect divin, et la doctrine de la causalité des Formes intelligibles. - Quant au livre très riche de Hugo H. Koning, Hesiod: the Other Poet. Ancient Reception of a Cultural Icon (Mnemosyne, Suppl. 325), Leyde-Boston, Brill, 2010, il offre un cadre général très approfondi à notre enquête, mais n'a pas pris en considération le dossier plotinien, et circonscrit son étude de Proclus au commentaire sur les Travaux (voir Index locorum, p. 433).

85. Émile Bréhier, Plotin. Ennéades, V, p. 150-151 (n. 1) dit très justement qu'il y a «quelque chose du langage messianique » dans ce texte de Plotin.

86. Nous ne pouvons que renvoyer, au sujet de ces doctrines très complexes, à l'édition commentée de H.D. Saffrey et L.G. Westerink, Proclus. Théologie Platonicienne. Livre V, Paris, C.U.F., 1987. Parallèlement, le commentaire de Proclus sur le Cratyle comporte de riches développements sur Ouranos, Cronos et 
Cronos dans un cadre systématique profondément différent de celui des Ennéades. La distinction entre les trois niveaux de l'Intelligible

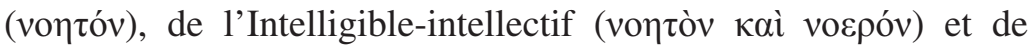

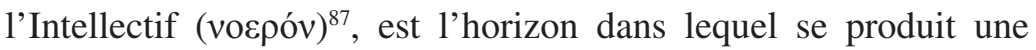
«descente» de la lignée Ouranos-Cronos-Zeus, qui s'éloigne fortement du niveau du Premier principe dans la très complexe hiérarchie des dieux, et s'articule à une triade Cronos-Rhéa-Zeus ${ }^{88}$. Ouranos n'est plus une figure de l'Un, mais il est comme rétrogradé jusqu'au diacosme intelligible-intellectif où il occupe la position

Zeus, à travers la version orphique du mythe : voir In Cratylum, scholies CV-CXI, p. 54, 12-64, 27 Pasquali (spéc. CVII, p. 57, 2 sqq. ; p. 59, 5 Cronos / кoрóvous), et Francesco Romano, Proclo. Lezioni sul «Cratilo» di Platone. Introduzione, Traduzione e Commento di F.R. («Symbolon », 7), Università di Catania-Roma (L'Erma di Bretschneider), 1989, p. 54-64 ; Luc Brisson, « La figure du Kronos orphique chez Proclus. De l'orphisme au néoplatonisme, sur l'origine de l'être humain », Revue de l'histoire des religions, 219, 4, 2002, p. 435-458, qui traduit et commente les scholies In Crat., CVII-CIX de Proclus (p. 441-445); et les textes étudiés par R. M. van den Berg, Proclus' Commentary on the "Cratylus » in Context. Ancient Theories of Language and Naming (Philosophia Antiqua, 112), Leyde-Boston, Brill, 2008, p. 156-160, 178, 184-187, 213-215. - Sur la vie intellective, qualifiée de «cronienne » par les «Théologiens » (c'est-à-dire les Orphiques), et le rapport entre Cronos et Zeus au sein de la première triade des dieux intellectifs, voir Proclus, In Parmenidem, I, 691, 6-13 (éd. Steel, I, p. 84-85) $=$ C. Luna et A.-Ph. Segonds, Proclus. Commentaire sur le "Parménide » de Platon, t. I, $2^{\mathrm{e}}$ partie, Livre I, Paris, CUF, 2007, I, 691, 9-18 (p. 98, et notes 4 et 6 ad loc. p. 284 ; lire aussi p. 274, la note 1 ad I, 684, 11 [p. 89], sur l'hebdomade des dieux intellectifs et la triade Cronos-Rhéa-Zeus).

87. La distinction entre le plan intelligible et le plan intellectif est expliquée dans la Théol. Plat., V, 1, p. 6, 6-9, 8 S.-W. Le livre III a étudié les hénades et les

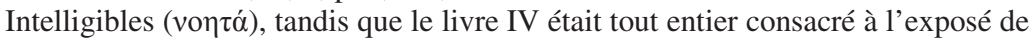

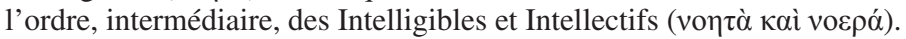

88. Cette structure complexe est facilement compréhensible à l'aide des tableaux récapitulatifs donnés par Hans Lewy, Chaldaean Oracles and Theurgy. Mysticism,

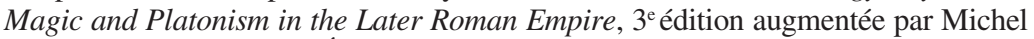
Tardieu (Collection des Études augustiniennes. Série Antiquité, 77) Paris 2011 (19561), Excursus VII, p. 483-484 (Synopsis of the three Theological Systems of Proclus [scil. platonicien, orphique, chaldaïque); Luc Brisson, «La place des Oracles Chaldaïques dans la Théologie Platonicienne », dans Alain-Philippe Segonds et Carlos Steel, éd. Proclus et la Théologie Platonicienne (Actes du Colloque International de Louvain, 13-16 mai 1998), Leuven-Paris 2000, p. 109-162 (voir p. 136-139 et Annexe p. 161) ; id., "Le commentaire comme prière destinée à assurer le salut de l'âme. La place et le rôle des Oracles Chaldaïques dans le commentaire sur le Timée de Platon par Proclus », dans Marie-Odile Goulet-Cazé et alii, éd. Le commentaire entre tradition et innovation. Actes du colloque international de l'Institut des Traditions Textuelles (Paris et Villejuif, 22-25 septembre 1999), Paris, Vrin, 2000, p. 329-353 (voir p. 344-346 et 353) ; et R.M. van den Berg, Proclus' Hymns. Essays, Translations, Commentary (« Philosophia Antiqua », 90), Leyde-Boston-Cologne, Brill, 2001, p. 40 (voir aussi p. 253, p. 312-313). 
médiane ${ }^{89}$, tandis que Cronos et Zeus se rangent dans le diacosme inférieur, le diacosme intellectif (qui est hebdomadique), ils constituent une triade ${ }^{90}$ avec Rhéa ${ }^{91}$, et sont des intellects intellectifs (voepoí) : mais dans ce diacosme Cronos est un intellect intelligible - car il est établi au sommet des dieux intellectifs -, tandis que Zeus, identifié au démiurge, est, à la limite inférieure, un intellect simplement intellectif $^{92}$. On est alors loin de l'Un-Bien, mais la figure de Cronos correspond à un niveau très précis, et éminent, de la réalité intellective. Et comme naguère l'intellect unique de Plotin, chacun de ces Intellects - qu'il s'agisse de Cronos ou de Zeus - réalise sous son mode propre l'unité du pensant et du pensé, de ce qui intellige et de ce qui est intelligé - nouvel avatar ${ }^{93} \mathrm{de}$ l'interprétation néoplatonicienne de la thèse aristotélicienne du $D e$ anima, livre 3, à propos de l'identité de la science et de ses objets immatériels ${ }^{94}$. Le projet de la Théologie Platonicienne étant de bâtir un système théologique total à partir de toutes les données fournies par les dialogues de Platon, Proclus effectue une synthèse de tous les textes mentionnant Cronos, dans le Cratyle ${ }^{95}$, le Politique ${ }^{96}$, les Lois (IV, 713 A 6-714 B 2) et le Gorgias (523 A 3-5) ${ }^{97}$, et les données platoniciennes s'accordent à celles du mythe dans sa version orphique, conformément au principe néoplatonicien de la

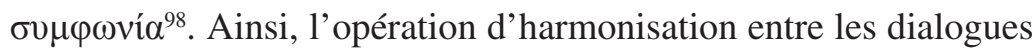

89. Proclus, Théol. Plat., IV, 5, p. 18, 23-22, 8 S.-W. La figure d'Ouranos se superpose alors à l'interprétation du Ciel du Phèdre comme entité supra-sensible (intelligible) et non plus cosmologique.

90. Proclus, Théol. Plat., V, 2, p. 9, 16-24 S.-W.

91. Proclus, Théol. Plat., V, 11, p. 35, 22-39, 24 S.-W.

92. Proclus, Théol. Plat., V, 12-32, p. 40, 1-120, 25 S.-W.

93. On se reportera à la section des Éléments de Théologie, Propositions 166-183, sur les intellects.

94. Lire par exemple Pierre Hadot, «La conception plotinienne de l'identité entre l'intellect et son objet. Plotin et le De anima d'Aristote», dans Gilbert Romeyer Dherbey et Cristina Viano, éd. Corps et âme : sur le De anima d'Aristote, Paris, Vrin, 1996, p. 367-376 ; repris dans P. Hadot, Plotin, Porphyre. Études néoplatoniciennes, Paris, Les Belles Lettres («L'âne d'or»), 1999, p. 267-278.

95. Proclus, Théol. Plat., V, 5, p. 20, 23-24, 21 S.-W.

96. Proclus, Théol. Plat., V, 6-8, p. 24, 23-30, 6 S.-W. Voir John Dillon, «The Neoplatonic Exegesis of the Statesman Myth », dans Christopher Rowe, éd. Reading the Statesman, volume cité supra (note 73), p. 364-374.

97. Proclus, Théol. Plat., V, 9, p. 30, 8-33, 16 S.-W.

98. Proclus, Théol. Plat., V, 10, p. 33, 18-35, 20 S.-W. (remarquer en 35, 5 l'étymologie Cronos / kopóvous, voir la note 2 ad loc. p. 167). Cf. les scholies au Cratyle mentionnées supra (note 86), et l'étude de Luc Brisson, « La figure du 
de Platon s'accompagne d'une harmonisation avec l'autorité d'Orphée, conforme au programme tracé par Syrianus et suivi scrupuleusement par Proclus ${ }^{99}$.

Il nous suffira de citer le texte de Théol. Plat. V, 3 qui expose avec clarté la généalogie platonicienne des dieux, et la place de Cronos, d'après le Cratyle :

... on peut se demander quel est l'ordre de dieux qui s'est séparé lui-même du royaume d'Ouranos pour prendre la tête de la classe intellective des dieux et être à titre premier le dispensateur de l'intellect selon l'enseignement même de Platon. Socrate dans le Cratyle <dit que ce n'est personne d'autre > que le très grand Cronos : car c'est cet intellect-là qu'il appelle l'intellect tout premier et le plus pur. Donc ce qu'il y a de plus élevé dans l'intellect divin et, comme il dit luimême, ce qu'il y a de plus pur, voilà quel est le dieu qui se détache lui-même de la classe ouranienne, et qui règne sur tous les dieux intellectifs, parce qu'il est entièrement rempli d'intellect, et qui plus est de l'intellect pur et du degré d'être intellectif tendu vers son plus haut sommet. Voilà pourquoi il est aussi Père du très grand Zeus, et Père purement et simplement: car le Père du père de tous les êtres (i.e. Zeus) a reçu à bien plus forte raison, je pense, la dignité paternelle. C'est donc Cronos qui est l'intellect premier, mais le très grand Zeus est aussi intellect, lui qui a une âme royale et un intellect royal, comme dit Socrate dans le Philèbe ; et par conséquent ce sont deux intellects et deux pères intellectifs, qui sont, parmi les intellectifs, l'un [scil. Zeus], intellectif, l'autre [scil. Cronos] intelligible ${ }^{100}$.

Kronos orphique chez Proclus ", à mettre en perspective à l'aide du recueil des études du même, Orphée et l'Orphisme dans l'Antiquité gréco-romaine, Londres, Aldershot Variorum («Collected Studies Series » 476), 1995.

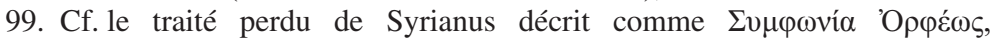

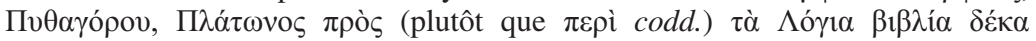
(«Harmonie d'Orphée, Pythagore, Platon avec les Oracles [chaldaïques], en dix

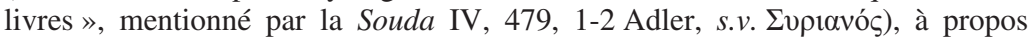
duquel on lira: Henri Dominique Saffrey, «Accorder entre elles les traditions théologiques : une caractéristique du néoplatonisme athénien », dans E. P. Bos et P. A. Meijer (éd.), On Proclus and his Influence in Medieval Philosophy, LeydeNew York-Cologne, E.J. Brill («Philosophia Antiqua», 53), 1992, p. 35-50 ; repris dans Le néoplatonisme après Plotin («Histoire des doctrines de l'Antiquité classique », 24), Paris 2000, p. 143-158.

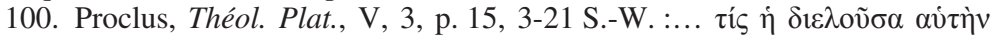

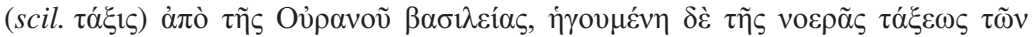

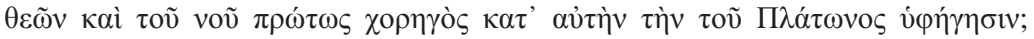

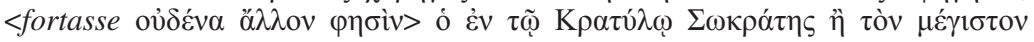

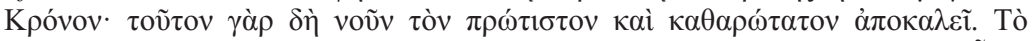

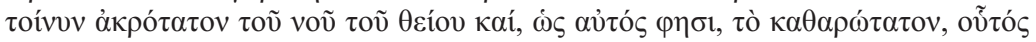

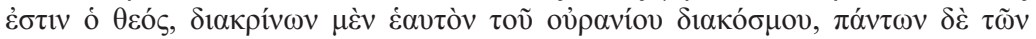

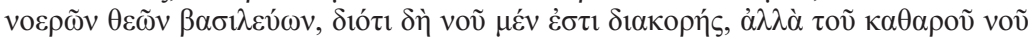

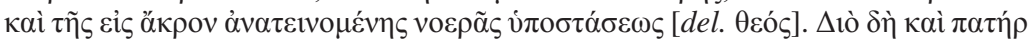




\section{UNE PHILOSOPHIE de L'HISTOIRE INTIMEMENT ARTICULÉE AU SYSTÈME NÉOPLATONICIEN}

La théologie systématique que nous lisons dans le livre $\mathrm{V}$ de la Théologie platonicienne permet donc, par sa netteté, de comprendre comment les expressions de Damascius, qui avait lui-même critiqué Proclus sur de nombreux points, et repris de façon souvent allusive - dans la version orphique - le mythe d'Ouranos, Cronos et Zeus dans le cadre de sa théologie ${ }^{101}$, imposent de toute évidence au lecteur l'idée d'une correspondance entre le premier âge de l'Humanité - régi par la Raison et par le Noṽ - et le niveau premier du diacosme intellectif. À ce titre, le premier âge, celui de « "la race [des hommes] parente des dieux" ( sous forme de fables les poètes assis sur le trépied de la Muse », est proprement pré-historique, car situé dans un passé mythique ou dans l'ordre Intellectif transcendant - au sens le plus propre, puisque

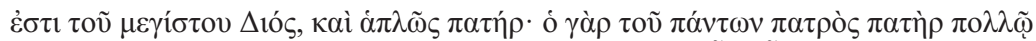

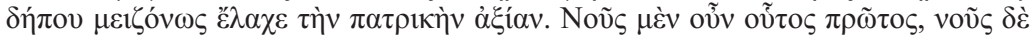

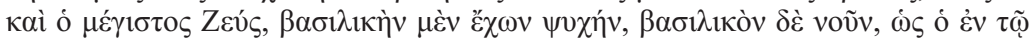

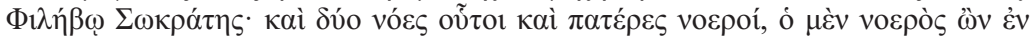

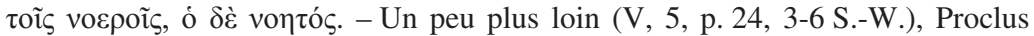

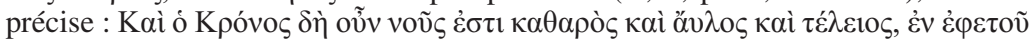

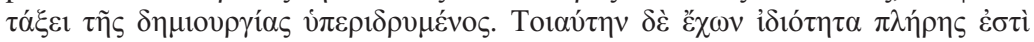

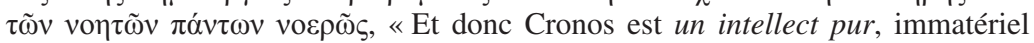
et parfait, installé dans l'ordre du désirable au-dessus de la démiurgie. Possédant cette propriété caractéristique, il est plein de tous les intelligibles, sous le mode

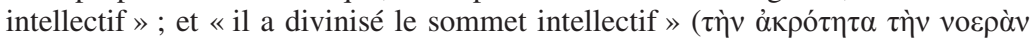

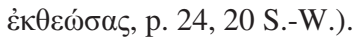

101. Damascius, Traité des Premiers principes, I, p. 6, 18-19 WesterinkCombès ; II, p. 92, 5-15 (voir les notes 3 et 6 ad loc. aux p. 256-257); III, p. 10, 10-24 (et la note 3 ad loc. p. 178-179) ; p. 27, 16-28, 12 ; p. 48, 8-12; p. 78, 4-24; et Commentaire du «Parménide » de Platon, I, CUF, Paris 1997, p. XXXV (tableau exposant la structure du diacosme intellectif et de son hebdomade, avec les correspondances entre Platon, la théologie orphique et les Oracles chaldaïques), et III, p. 1, 1-34, 4 Westerink $†$-Combès-Segonds (exposé du premier ordre des intellectifs; cf. Notice, p. LXXVIII, même tableau), en particulier p. 8, 19 (Kó́vos / Kopóvous) ; p. 11, 1-14, 25 ; p. 15, 15-19; p. 17, 23-26 (et note 1 ad loc., p. 220) ; p. 18, 23-25 (et note 12 ad loc., p. 221) ; p. 20, 2-4 ; p. 22, 11 ; p. 25,

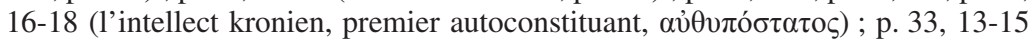
W.-C.-S. On pourra se reporter aussi aux notes à la traduction de Marie-Claire Galpérine, Damascius. Des Premiers principes. Apories et résolutions, Lagrasse, éditions Verdier, 1987, voir Index nominum, p. 653, s.v. Kronos (par ex. p. 363 n. 129 ou p. 499-500 n. 13). - Il n'est évidemment pas possible d'entreprendre ici une étude de la critique adressée par Damascius à Proclus.

102. Voir supra, note 27. 
les hommes, alors, vivaient avec les dieux, et comme les dieux ${ }^{103}$. À l'inverse, l'âge présent, celui de l'Empire chrétien, celui « des hommes qui à présent vivent dans la génération » (oi võv $\dot{\varepsilon} v$ iñ $\gamma \varepsilon v \varepsilon \dot{\sigma \varepsilon \varepsilon} \pi \mathrm{o} \lambda \iota \tau \varepsilon v o ́ \mu \varepsilon v o \imath ~ \alpha ̋ v \theta \rho \omega \pi \mathrm{ol})$ correspond ontologiquement et

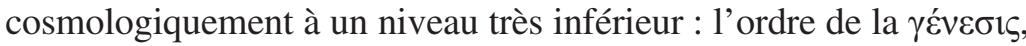
horizon naturel de toutes les passions irrationnelles qui habitent les âmes des Chrétiens ${ }^{104}$, au plus loin du règne de l'Intellect cronien.

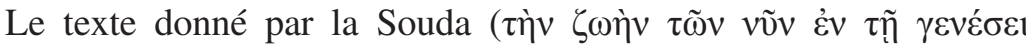

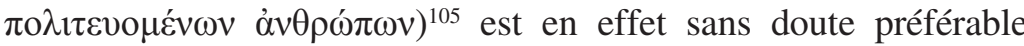

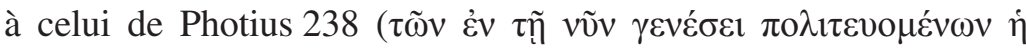
$\zeta \omega \eta ́)$, comme l'ont proposé dans leurs reconstitutions et traductions Rudolf Asmus ${ }^{106}$ et Polymnia Athanassiadi ${ }^{107}$ - même si le texte de

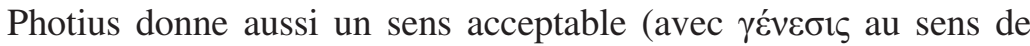
《 génération », «âge » ${ }^{108}$ ), quoique plus faible.

Si l'on admet donc le texte de la Souda, le schéma de dégradation se comprend dans un cadre ontologique proprement néoplatonicien, entre d'une part l'ordre Intellectif transcendant et d'autre part la zone sublunaire (le monde de la génération et de la corruption) qui se situe au niveau inférieur de la Procession. Si l'on se souvient aussi que l'âge de Cronos, dans les Travaux d'Hésiode, est un âge de justice, et que dans l'exposé platonicien des Lois, IV, 713 A 2-714 A 2, il se

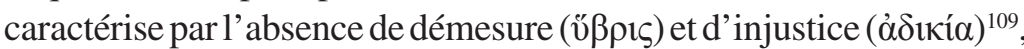

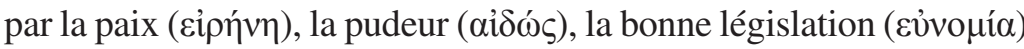

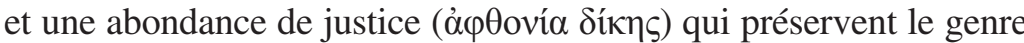

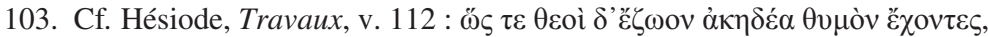
«Ils vivaient comme des dieux, le cœur libre de soucis » (Mazon).

104. Voir Proclus, In Cratylum, CXXV, p. 74, 5-15 Pasquali, qui assigne aux âmes des chrétiens le Tartare et « la région de l'Univers la plus dépourvue de lumière et d'ordre »; et Ph. Hoffmann, « Un grief anti-chrétien chez Proclus : l'ignorance en théologie », spéc. p. 196 et note 120. - Selon Damascius, la vie irrationnelle est «titanique» : voir par exemple L.G. Westerink, éd. The Greek Commentaries on Plato's Phaedo. Volume II : Damascius, Amsterdam-Oxford-New York, 1977, North-Holland Publishing Company, p. 32-33, In Phaedonem I, 9, (I 86-87 N.).

105. Souda, IV, 853, 2-3 Adler. Voir supra, p. 748.

106. R. Asmus, Das Leben des Philosophen Isidoros, p.14 : «Dergestalt und noch viel niedriger schilderte er auch das Leben der Menschen, welche sich jetzt in der Welt des Werdens politisch betätigten ».

107. P. Athanassiadi, Damascius. The Philosophical History, p. 97 (et n. 44) : « And he showed the life of the men who are now in the service of generation to be much baser even than this».

108. Comme chez Platon, Phèdre, 252 D 3 (

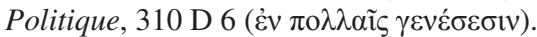

109. Platon, Lois, IV, 713 C 7. 


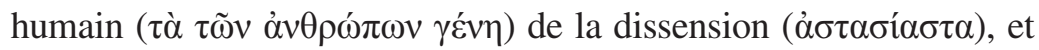
lui assurent le bonheur $\left(\varepsilon \hat{\delta} \delta \alpha f_{\mu o v} \alpha\right)^{110}$; - et si l'on songe d'autre part que pour ces farouches opposants à l'Empire chrétien que sont les derniers néoplatoniciens, la situation présente, et les hommes d'aujourd'hui, sont essentiellement mauvais, injustes - au sens précis de la République de Platon ${ }^{111}$ - et correspondent à un âge de tyrannie ${ }^{112}$, on peut alors proposer le tableau suivant :

110. Platon, Lois, IV, 713 E 1-3.

111. C'est ce que j' ai tenté de démontrer dans mon article « Un grief antichrétien chez Proclus : l'ignorance en théologie », voir p. 163-164, 169-170, 196.

112. Simplicius, In Epicteti Enchiridion, p. 138, 18-19 Dübner = E(pilogus), 3-4, p. 454 Hadot $^{1}$, évoque les «circonstances tyranniques» ( $\pi \varepsilon \rho i ́ \sigma \tau \alpha \sigma ı \varsigma)$ dans lesquelles il a écrit son commentaire. H.D. Saffrey, «Le thème du malheur des temps chez les derniers philosophes néoplatoniciens ", cité supra (note 12), p. 426-429 [212-214], a signalé ce passage, après avoir traduit et commenté un autre texte du Commentaire sur le Manuel d'Épictète (p. 35, 22-46 Dübner $=$ XIV, 16-35, p. 256-257 $\mathrm{Hadot}^{1}$ ) dans lequel Simplicius,

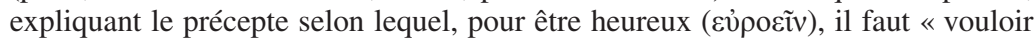
que les événements se produisent tels qu'ils se produisent », accorde que cela peut sembler à certains « trop dur et impossible », et évoque les nombreux malheurs qui

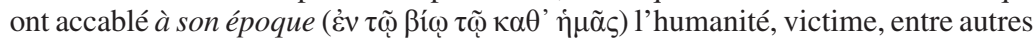

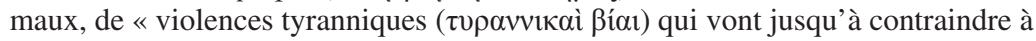
l'impiété » et de mesures fatales à la culture $(\pi \alpha 1 \delta \varepsilon i ́ \alpha)$ et à la philosophie : de tels malheurs ne peuvent être tolérés, et même voulus, que par « un homme qui veut le

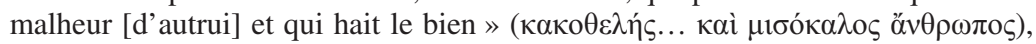
peut-être - selon Saffrey - l'empereur Justinien lui-même (527-565). Mais I. Hadot, dans plusieurs publications (Le problème du néoplatonisme alexandrin. Hiéroclès et Simplicius, Paris, Études Augustiniennes, 1978, p. 33-40 ; Simplicius. Commentaire sur le Manuel d'Épictète. Introduction et édition critique du texte grec [Philosophia Antiqua, 66], Leyde-New York-Cologne, Brill, 1996, p. 8-20, et Le néoplatonicien Simplicius à la lumière des recherches contemporaines. Un bilan critique, Sankt Augustin, Academia Verlag, 2014, p. 166-170) a dénié aux textes et expressions de Simplicius sur l'âge de tyrannie au milieu duquel doit vivre le philosophe (cf. aussi un long développement sur le thème du philosophe dans l'État corrompu, XXXII, 163-234, p. 313-316 Hadot $^{1}$, p. 64, 52-66, 36 Dübner) toute portée autobiographique permettant de dater et de localiser avec précision la rédaction du commentaire, et elle a montré que ces développements, de portée générale (mais néanmoins applicables, de toute évidence, au régime chrétien), relèvent de lieux communs déjà bien attestés chez Platon et les Stoïciens - ce qui selon elle ruinerait les analyses d'Alan Cameron, " The Last Days of the Academy at Athens », Proceedings of the Cambridge Philological Society, 195 (N.S.), 1969, p. 7-29 (repris dans Literature and Society in the Early Byzantine World, Londres 1985, n 13, p. 7-30), et «La fin de l'Académie », dans Le Néoplatonisme. Actes $d u$ Colloque international du CNRS (Royaumont, 9-13 juin 1969), Paris, Éditions du CNRS, 1971, p. 281-290. Sur ce débat, qui sort de notre sujet, voir aussi mes quelques observations, dans «Un grief antichrétien chez Proclus», p. 170-174. - Le ch. 32 de l'In Epicteti Enchiridion a par ailleurs été traduit et commenté par 


\begin{tabular}{|c|c|c|}
\hline $\begin{array}{l}\text { vie sous le règne de Cronos } \\
\text { Prédominance de la Raison } \\
\text { Parenté avec les dieux }\end{array}$ & $\begin{array}{l}\text { âge d'or } \\
<\text { justice> }\end{array}$ & $\begin{array}{l}\text { Niveau intellectif : Kpóvos } \\
\text { (père de l'Intellect } \\
\text { démiurgique }=\text { Zeus) }\end{array}$ \\
\hline $\begin{array}{l}\text { Prédominance du } \theta v \mu \text { ó } \varsigma \\
\text { Guerres et } \varphi \imath \lambda o \tau \imath \mu i ́ \alpha\end{array}$ & $\begin{array}{l}\text { Temps historiques } \\
\text { de la Grèce } \\
\text { (jusqu'au IV }{ }^{\mathrm{e}} \text { siècle) }\end{array}$ & \\
\hline $\begin{array}{l}\text { Prédominance de l' } \dot{\varepsilon} \pi \imath v \mu i^{\prime} \alpha \\
\text { et des passions mauvaises }\end{array}$ & $\begin{array}{l}\text { Temps présent (ṽ̃v) } \\
\text { Empire chrétien } \\
<\text { injustice }>\end{array}$ & $\begin{array}{l}\text { Niveau de la } \gamma \varepsilon ́ v \varepsilon \sigma ı \varsigma \\
\text { Zone sublunaire } \\
\text { (lieu cosmologique } \\
\text { des passions) }\end{array}$ \\
\hline
\end{tabular}

\section{VII. «VIE SOUS LE RÈgne de Cronos » VS. « MALHEURS DES TEMPS » : UNE MISE EN CONTEXTE}

\section{L'idéal de la République était vivant chez les derniers} néoplatoniciens, qui maintenaient la flamme de la pensée politique de tradition platonicienne ${ }^{113}$. Si l'on en croit le témoignage d'Agathias ${ }^{114}$ - dont on ne peut toutefois exclure qu'il ait voulu railler les philosophes en les présentant sous un jour naïf ${ }^{115}-$,

Dominic O'Meara, «Simplicius on the Place of the Philosopher in the City (In Epictetum, ch. 32) », Mélanges de l'Université Saint-Joseph, 57, 2004, p. 89-98.

113. Lire l'ouvrage fondamental de Dominic J. O'Meara, Platonopolis. Platonic Political Philosophy in Late Antiquity, Oxford, Oxford University Press, 2003.

114. L'ensemble du texte d'Agathias, Histoires, II, 30, 3-31, 4 ; p. 80, 5-81, 21 Keydell (Corpus Fontium Historiae Byzantinae, 2, Berlin 1967), a été traduit par Ilsetraut Hadot, Le problème du néoplatonisme alexandrin, p. 21-23, et Simplicius. Commentaire sur le Manuel d'Épictète (1996), p. 9-10 (note 4). Voir aussi ead., Le néoplatonicien Simplicius à la lumière des recherches contemporaines, p. 19-22, et la notice de Richard Goulet et Elisa Coda, «Simplicius », DPhA, VI, Paris 2016, S 92, p. 341-394 (voir p. 343-346). Il serait hors de propos de présenter et de discuter le dossier très complexe du séjour des philosophes néoplatoniciens en Perse. - On dispose aussi pour le texte d'Agathias d'une traduction en anglais (J.D. Frendo, Agathias. The Histories [Corpus Fontium Historiae Byzantinae, II/A], Berlin-New York 1975, voir p. 62-67), et d'une traduction en français de Pierre Maraval, Agathias. Histoires. Guerres et malheurs du temps sous Justinien, Paris, Les Belles Lettres («La roue à livres », 50), 2007, suivie par Richard Goulet, notice « Simplicius », p. 343-344.

115. Sur ce point, important pour la question qui nous occupe, voir les remarques d'Ilsetraut Hadot, dans Le problème du néoplatonisme alexandrin, p. 21-22 note 29 [la notice d'Agathias est hostile à Chosroès], et p. 24 et note 35 ; «La vie et l'œuvre de Simplicius d'après des sources grecques et arabes », dans Simplicius : sa vie, son æeuvre, sa survie, cité supra (note 63), p. 7-9 ; Simplicius. Commentaire sur le Manuel d'Épictète [1996], p. 12 et note 15. I. Hadot pense (contre l'opinion d'Averil Cameron, Agathias, Oxford, 1970, p. 101, et de moimême) qu'Agathias a voulu tourner en dérision les philosophes néoplatoniciens, 
Damascius et ses compagnons pourraient s'être lancés dans l'aventure perse, après 529, dans des dispositions d'esprit bien dignes de platoniciens, puisqu'ils croyaient que chez les Perses était réalisée la coïncidence de la philosophie et de la royauté, dans un État juste ${ }^{116}$ : on peut imaginer en ce cas qu'ils aient eu à l'esprit les mots de Platon affirmant la possibilité que l'État parfait se réalise

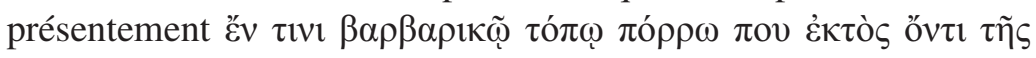

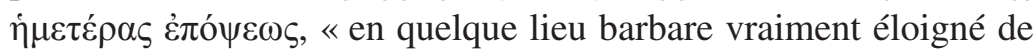
notre regard $»^{117}$. On sait quelle fut - toujours selon Agathias - leur

pour lesquels il n'aurait eu aucune sympathie. En ce cas et à la limite, la mention de leur attachement à l'idéal de Platon pourrait n'être qu'un trait destiné à souligner leur naïveté, et dont il n'y aurait rien à tirer pour notre présente enquête. Dans la notice «Damascius» du Dictionnaire des Philosophes antiques (II, 1994), p. 560, je considérais au contraire le témoignage d'Agathias comme favorable aux néoplatoniciens. Il me semble prudent, ici, de signaler au lecteur ce problème, qui touche à l'interprétation d'ensemble du texte d'Agathias, et qui conditionne la façon de comprendre la phrase «ils étaient persuadés que les dirigeants, chez [les Perses] étaient parfaitement justes et tels que le veut le discours de Platon, la royauté coüncidant avec la philosophie » (voir la note suivante). Selon moi, il est tout à fait plausible, étant donné la réputation favorable dont jouissaient alors les Perses, que Damascius et ses compagnons aient sincèrement pensé qu'ils trouveraient la $\pi \mathrm{o} \lambda \imath \tau \varepsilon i ́ \alpha$ juste dans leur royaume, et qu'ils aient été animés d'un intérêt profondément platonicien au début de leur aventure. D'ailleurs Ilsetraut Hadot ne produit-elle pas (cf. loc. cit. supra) des arguments en faveur de l'opinion favorable que l'on pouvait avoir des Perses, comme la tolérance et la liberté religieuse dont jouissait l'Université nestorienne de Nisibe, foyer de culture grecque ? Et la notice de Michel Tardieu, « Chosroès », dans DPhA, II, Paris 1994, C 113, p. 309-318, montre assez que l'excellente réputation de Chosroès n'était pas usurpée, en dépit du portrait malveillant qu'en brosse Agathias.

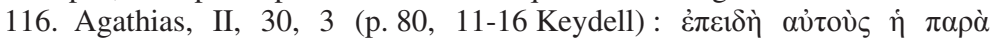

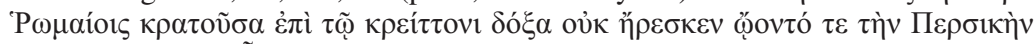

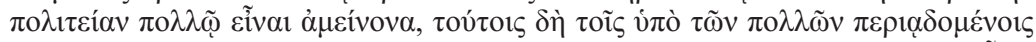

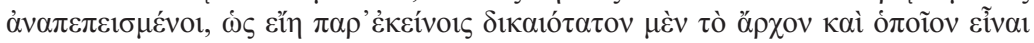

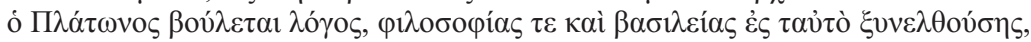

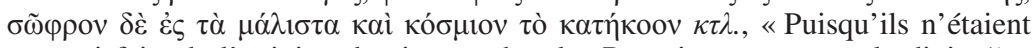
pas satisfaits de l'opinion dominante chez les Romains concernant le divin (i.e. le christianisme), et qu'ils croyaient que le régime politique des Perses était bien meilleur, comme tout le monde faisait l'éloge des Perses, ils étaient persuadés que les dirigeants, chez ces gens-là, étaient parfaitement justes et tels que le veut le discours de Platon, la royauté coïncidant avec la philosophie, et que les sujets étaient, au plus haut point, de mœurs tempérantes et honnêtes etc. » (trad. Hadot, légèrement modifiée). - Dominic O'Meara, «Simplicius on the Place of the Philosopher in the City », p. 96, parle de « a philosopher's folly ».

117. Platon, République, VI, 499 C 9-D 1. - P. Athanassiadi, Damascius. The Philosophical History, p. 49, me semble résumer de façon très plausible l'état d'esprit de Damascius : « ... he conceived the idea of transferring intact to another land the edifice that he had been building over the years. Platonic reminiscences of the constitutionally just character of the Persian king, fashioned by the ideal 
déception en découvrant l'injustice qui régnait chez les Perses, et dans quelles conditions ils revinrent s'installer dans l'Empire byzantin. Si l'on ajoute foi au texte d'Agathias, le projet politique qui aurait animé le voyage d'exil des philosophes auprès du roi Chosroès - un souverain éclairé118 - peut apparaître comme une mise en acte de la philosophie de l'Histoire exposée dans la Vie d'Isidore: les philosophes étaient, au sein d'un présent corrompu, des ferments de Raison qui ne renonçaient pas à rechercher chez les ennemis de Byzance une $\pi$ o $\lambda \imath \tau \varepsilon i ́ \alpha$ juste, qui fît contrepoint à la tyrannie de l'Empire chrétien.

Pour Damascius, en tout cas, il est possible au philosophe de vivre présentement, au sein d'un monde corrompu, la vie de l'âge de Cronos. C'est ce que prouve, selon la Vie d'Isidore, la figure du pieux ermite païen Sarapion ${ }^{119}$, qui vivait à Alexandrie. Homme d'une absolue simplicité, ami d'Isidore, c'était un «chercheur de vérité au naturel contemplatif », qui dédaignait les subtilités trop techniques de la philosophie pour entrer en communion avec les «notions de plus grande ampleur et de nature à produire plus intensément la possession divine $»^{120}$. Seule la «théologie » orphique intéressait Sarapion ${ }^{121}$, qui s'entretenait fréquemment à ce sujet avec Isidore, en raison de l'extrême compétence

educational methods, mingled in his mind with the language of contemporary Sassanian propaganda and, suddenly, Ctesiphon appeared as the ideal philosophical abode ».

118. Michel Tardieu, notice «Chosroès », citée supra note 115 (notamment aux p. 313-314).

119. Voir le rapprochement effectué par R. Asmus, «Zur Rekonstruktion... », ByzZ, 18, 1909, p. 448 ; et la notice de Richard Goulet, «Sarapion», DPhA, VI, Paris 2016, S 11, p. 121-122. Les textes sur Sarapion correspondent aux fragments *33-*41 de Zintzen (p. 31-37), mais la Souda offre (IV, 323, 28-325, 9 Adler) un texte continu, repris (avec raison me semble-t-il) et traduit par P. Athanassiadi, Damascius. The Philosophical History, p. 264-269 (=fragments 111 et 112 A), voir aussi Introduction, p. 23-24 et note 16, et p. 66-67 sur la méthode d'édition. - Une belle évocation de Sarapion se lit chez André-Jean Festugière, «Proclus et la religion traditionnelle », repris dans Études de philosophie grecque, Paris, Vrin, 1971, p. 575-584 (voir p. 583-584, où plusieurs passages sont traduits).

120. Souda IV, 324, 17-20 Adler = Fragment *41 Zintzen (p. 37, 6-8):

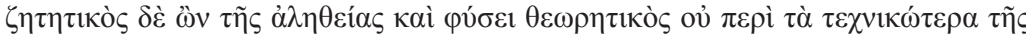

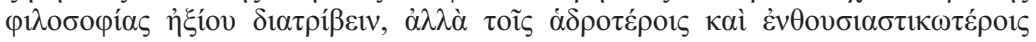

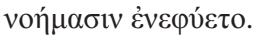

121. Cela tend à prouver que les écrits orphiques circulaient à Alexandrie. Sur ce point, voir Ilsetraut Hadot, Le néoplatonicien Simplicius à la lumière des recherches contemporaines, cité supra (note 112), p. 17 ; et Athenian and Alexandrian Neoplatonism and the Harmonization of Aristotle and Plato, traduit 
scientifique de celui-ci en théologie ${ }^{122}$, et Sarapion n'était soucieux que de «toujours se rassembler et se concentrer, autant qu'il le pouvait, en direction de la [partie] intérieure et plus indivise [en lui] $»^{123}$, et qui précisément est la partie selon laquelle se produit

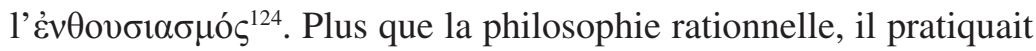

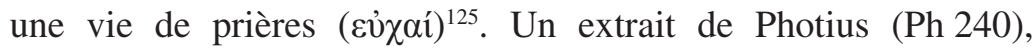
rapproché par Zintzen des témoignages sur Sarapion, comporte une description des trois étapes de la prière (concentration sur soimême, dépassement de la rationalité discursive jusqu'au niveau du Noṽ , puis possession par la divinité ${ }^{126}$, qui explique que la prière

par Michael Chase, Leyde-Boston, Brill (« Studies in Platonism, Neoplatonism, and the Platonic Tradition », 18), 2015, p. 12-13.

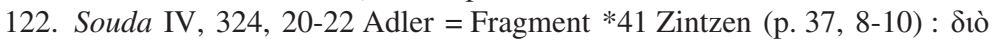

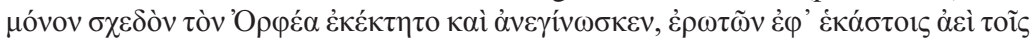

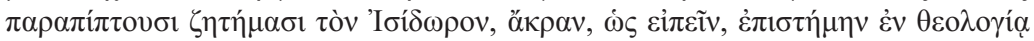
$\pi \rho \circ \beta \varepsilon \beta \lambda \eta \mu \varepsilon ́ v o v$.

123. Souda IV, 324, 24-26 Adler $=$ Fragment $* 33$ Zintzen (p. 31, 17-33, 2) :

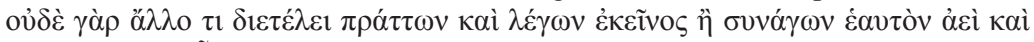

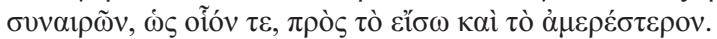

124. Comme le montre un rapprochement très éclairant avec un passage du commentaire d'Olympiodore sur l'Alcidiade (In Alcibiadem, 8, 10-14 Westerink [p. 9]), traduit par Festugière, « Proclus et la religion traditionnelle », p. 583.

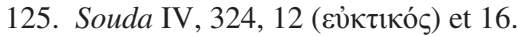

126. Photius, Codex 242, 350 a 24-31 ; Zintzen p. 35 et 37 (fr. 40) [avec les

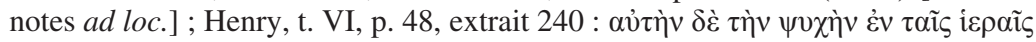

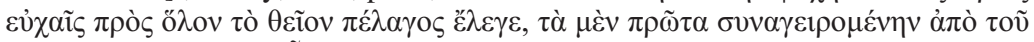

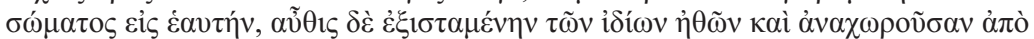

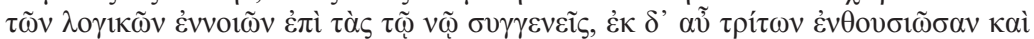

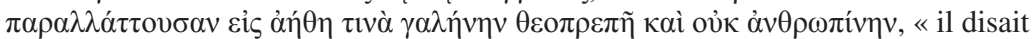
que l'âme elle-même, dans les prières sacrées, aspirant à tout l'océan du divin, tout d'abord se sépare du corps pour se concentrer sur elle-même ; ensuite, elle sort des modes d'être qui lui sont propres et se retire des pensées rationnelles pour atteindre celles qui sont de même nature que l'Intellect ; en troisième lieu, elle est possédée par le divin et elle change de niveau pour entrer dans une sérénité insolite, qui est divine, et non plus humaine ». Les trois étapes sont donc : la séparation de l'âme et du corps et la conversion de l'âme vers elle-même (niveau de la raison discursive = la $\delta$ ióvor $\alpha$ ); puis une remontée au-delà de la pensée «logique » jusque dans la pensée non discursive de l'Intellect; enfin, l'installation dans l'ordre du divin. Je voudrais ajouter à la note $a d$ loc. de Zintzen (p. 35 et 37) que la doctrine de la prière exposée par Jamblique (Réponse à Porphyre $=$ De Mysteriis, V, $26=$ p. 237, 7-240, 17 Parthey = p. 176, 20-179, 7 Saffrey-Segonds-Lecerf) présente une progression sensiblement différente, et formulée de façon plus complexe, même si le terme ultime est aussi une installation spirituelle dans le monde des dieux, comme d'ailleurs chez Proclus, In Timaeum, I, 211, 8-212, 28 Diehl (traduction Festugière, II, p. 32-35). Sur cette question, voir Ph. Hoffmann, «Érôs, Alètheia, Pistis... et Elpis. Tétrade chaldaïque, triade néoplatonicienne (OC 46 des Places, p. 26 Kroll) », dans Helmut Seng et Michel Tardieu, éd. Die Chaldaeischen 
permet d'atteindre des pensées, des « notions » (Ëvvolal) qui soient « de même nature que l'Intellect », c'est-à-dire, probablement, les

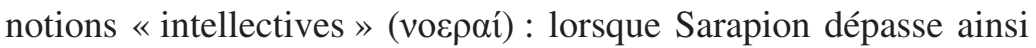
les subtilités de l'argumentation philosophique pour atteindre la

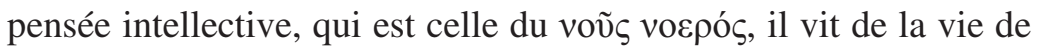
l'Intellect-Cronos. Dans cette perspective, que l'on peut qualifier de «supra-rationnelle», Sarapion ne possédait que deux ou trois livres contenant notamment les poèmes orphiques ${ }^{127}$, qui se situaient au sommet du cursus anagogique néoplatonicien, au-delà même de l'enseignement philosophique platonicien qui avait culminé avec la lecture du Parménide - mais en concurrence, on le sait, avec les Oracles Chaldaïques ${ }^{128}$. N'ayant pas de descendance humaine (il avait maîtrisé les nécessités du corps et conservé sa virginité tout au long de sa vie) ${ }^{129}$, il transmit ses livres à Isidore en un acte de légitimation spirituelle. Damascius nous dit que Sarapion demeurait la plupart du temps dans sa maison, «menant une vie non pas humaine mais à proprement parler divine»

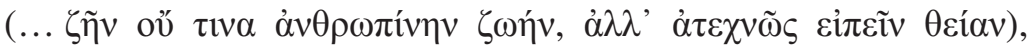
essentiellement consacrée à la prière ${ }^{130}$, et qu'on avait l'impression de « contempler en lui la vie légendaire dans l'âge de Cronos » ( $\dot{\varepsilon} v$

Orakel : Kontext, Interpretation, Rezeption (Actes du Colloque de l'Université de Konstanz, 15-18 novembre 2006), Heidelberg, Universitätsverlag Winter, 2011, p. 255-324 (aux p. 287-301) ; repris sous une forme différente dans Mariano Delgado, Charles Méla, Frédéric Möri, dir. Orient-Occident. Racines spirituelles de l'Europe. Enjeux et implications de la translatio studiorum dans le judaïsme, le christianisme et l'islam de l'Antiquité à la Renaissance (Actes du colloque international, Fribourg, 16-19 novembre 2009), Paris, Éditions du Cerf, 2014, p. 63-136 (aux p. 98-112).

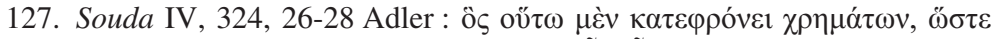

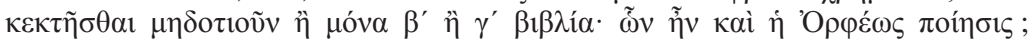
voir aussi 325, 1-3 (sur le legs de ces livres à Isidore).

128. Parmi l'abondante bibliographie consacrée au cursus d'étude néoplatonicien, lire en particulier: Marie-Odile Goulet-Cazé, «L'arrière-plan scolaire de la Vie de Plotin. Excursus : le programme d'enseignement dans les écoles néoplatoniciennes », dans Luc Brisson et alii, Porphyre. La Vie de Plotin, t. I, Paris, Vrin («Histoire des doctrines de l'Antiquité classique», 6), 1982, p. 277-280, aux p. 279-280 ; et Marinus. Proclus ou Sur le bonheur, ch. 26-27 (p. 30-32 de l'édition Saffrey-Segonds-Luna, Paris, CUF, 2001, et notes 5 et 7 aux p. 150-152), où l'on apprend comment Proclus avait enrichi de scholies marginales un exemplaire du Commentaire de Syrianus aux Rhapsodies orphiques.

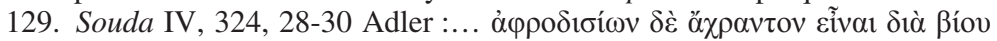
$\pi \alpha v \tau o ́ s$.

130. Souda IV, 324, 14-17 Adler $=$ Fragment $* 39$ Zintzen (p. 35). 


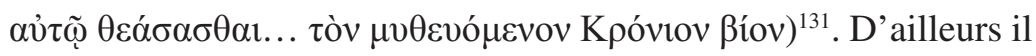
serait resté inconnu si un dieu n'avait pas voulu offrir aux hommes, à travers Sarapion, un exemple réel, un modèle $(\pi \alpha \rho \alpha ́ \delta \varepsilon r \gamma \mu \alpha)$ de la vie sous l'âge de Cronos, afin que cette formule ( $\lambda$ ó $\gamma_{0} \varsigma$ ) ne semble pas être seulement un mythe $(\mu \tilde{v} \theta o \varsigma)$, et qu'elle reçoive ainsi la

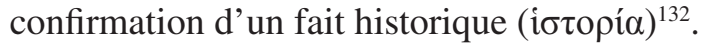

Concluons par quelques réflexions d'ordre historique. Dans son article sur le thème du «malheur des temps », le P. Saffrey a souligné très justement le contraste entre la modération de ton que Proclus observe lorsqu'il introduit, de façon voilée, des allusions aux Chrétiens et au christianisme ${ }^{133}$, et la «violence rare» qui traduit, notamment dans les extraits conservés par la Souda, la « colère » de Damascius devant la situation présente qui est celle de l'Empire byzantin ${ }^{134}$. La datation de la Vie d'Isidore (avant 526, et peut-être entre 517 et 526) ${ }^{135}$ interdit de voir dans ces invectives une allusion précise au règne de Justinien (devenu empereur en 527), et la critique des Chrétiens revêt un caractère trop général pour que l'on puisse tirer de notre texte une quelconque indication

131. Souda, IV, 324, 23-24 Adler.

132. Souda, IV, 324, 32-34 Adler. Un peu plus loin (325, 3-9), Damascius brosse une antithèse forte entre la simplicité de Sarapion, qui mène une vie à la fois «cronienne» et «jovienne», et le personnage «typhonien» de Pamprépios de Panopolis (440-484), « une bête encore plus retorse que Typhon, et d'une enflure

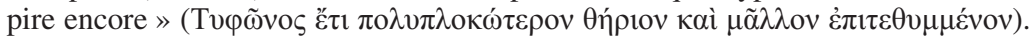
Sur Pamprépios, poète, grammairien, homme politique païen, lire P. Athanassiadi, Damascius, Introduction p. 24, 38, et fr. 112, p. 268-271, voir p. 269 note 301 la récapitulation des principaux événements de la vie de Pamprépios d'après son horoscope ; Richard Goulet, notice «Pamprépius de Panopolis », dans DPhA, Va, Paris 2011, P 18, p. 116-125 (p. 123 sur notre texte). Malgré ses convictions religieuses païennes, il représente aux yeux de Damascius le contraire de la philosophie.

133. Lire à ce sujet H. D. Saffrey, «Allusions antichrétiennes chez Proclus, le diadoque platonicien », Revue des Sciences philosophiques et théologiques, 59, 1975, p. 553-563 ; repris dans Recherches sur le néoplatonisme après Plotin, Paris, Vrin (« Histoire des doctrines de l'Antiquité classique», 14), 1990, p. 201-211; spéc. p. 561-562 [209-210]. La prudence de Proclus pourrait s'être accompagnée du sentiment que le christianisme n'était pas destiné à durer.

134. Henri Dominique Saffrey, «Le thème du malheur des temps chez les derniers philosophes néoplatoniciens », cité supra (note 12), p. 423-426 [209-212].

135. Voir supra, p. 739. 
chronologique. Damascius s'en prend à la politique des empereurs chrétiens, et ce texte s'inscrit dans le phénomène très concret de l'opposition païenne à cette politique depuis le $\mathrm{IV}^{\mathrm{e}}$ siècle, dont plusieurs épisodes sont rapportés dans l'ouvrage ${ }^{136}$. Par ailleurs, il est certain que la rédaction de la Vie d'Isidore est à mettre en relation avec le projet de grande ampleur de Damascius, devenu diadoque de l'Académie à Athènes (vers 515 ?) ${ }^{137}$ : réaffirmation de l'autorité de Platon, restauration et pérennisation de l'École et de ses programmes philosophiques, grâce notamment à l'apport de forces vives venues d'Alexandrie ${ }^{138}$. Au cœur d'un état des choses corrompu par l'غ̇ $\pi \imath v \mu$ ía, le renouveau de l'École marquait la présence active du $\lambda$ ó $\gamma$ os, et le texte que nous venons d'étudier situe dans l'histoire du Monde le projet du scolarquat de Damascius, qui était résolument tourné vers le futur. L'on songera alors que la rigueur des mesures prises par Justinien s'explique sans aucun doute, non comme le coup de grâce donné à une école païenne moribonde, mais comme un acte fort contre un foyer de résistance plein de vitalité institutionnelle et intellectuelle $e^{139}$ - attestée par les œuvres immenses de Damascius et, plus tard, de Simplicius. L'ambition de Damascius était de rétablir la Philosophie dans toute son ampleur, par la restauration du cursus complet, qui comprenait les études aristotéliciennes: de ce programme, Simplicius devait être l'un des acteurs, à travers ses grands commentaires sur Aristote. Le même Simplicius, dans sa polémique contre Jean Philopon, compare les «nouveautés» de la pensée chrétienne aux Jardins

136. Lire à ce sujet Raban von Haehling, «Damascius und die heidnische Opposition im 5. Jahrhundert nach Christus. Betrachtungen zu einem Katalog heidnischer Widersacher in der Vita Isidori», Jahrbuch für Antike und Christentum, 23, 1980, p. 82-95, et, du même auteur, « Heiden im griechischen Osten des 5. Jahrhunderts nach Christus », Römische Quartalschrift für christliche Altertumskunde und Kirchengeschichte, 77, 1982, p. 52-85.

137. La date n'est pas assurée : voir la notice «Damascius », dans DPhA, II, p. 547, et P. Athanassiadi, Damascius. The Philosophical History, p. 43 et 45.

138. Voir la notice «Damascius », dans DPhA, II, p. 555-559; et l'analyse convaincante de P. Athanassiadi, Damascius. The Philosophical History, p. 42-48 : l'Histoire philosophique "was to be a cultural manifesto weaving around the historical leitmotiv of the Platonic diadoche the various themes of the "education of the future". These themes consisted in the cultivation of philosophy for the few and in the worship of the holy for all (...)» (p. 47).

139. Voir la notice « Damascius », dans DPhA, II, p. 557 ; et P. Athanassiadi, Damascius. The Philosophical History, p. 45. 
$\mathrm{d}^{\prime}$ Adonis ${ }^{140}$ : preuve que, pour lui, comme naguère pour Proclus, et très probablement pour les autres néoplatoniciens, tout cela n'était qu'un mauvais moment à passer ${ }^{141}$. Il était dans l'ordre platonicien des choses que la masse (les $\pi \mathrm{o} \lambda \lambda$ oí) ait son heure - transitoire de triomphe. Dans l'exposé sur les trois âges de l'Humanité, la détestation virulente du présent ne signifie pas que Damascius ait considéré comme une chose impossible la réalisation d'une $\pi$ o $\lambda \iota \tau \varepsilon i ́ \alpha$ conforme aux exigences de la Raison, telle que la définissait la théologie néoplatonicienne ${ }^{142}$, et le renouveau de l'École s'inscrit dans cet horizon.

Les faits, on le sait, se chargèrent de démentir ce qui était une illusion.

Philippe.Hoffmann@ephe.sorbonne.fr

140. Simplicius, In De caelo, p. 25, 34-36 Heiberg. Voir Ph. Hoffmann, «Sur quelques aspects de la polémique de Simplicius contre Jean Philopon : de l'invective à la réaffirmation de la transcendance du Ciel », cité supra (note 63), aux p. 196-197.

141. H.D. Saffrey, «Allusions antichrétiennes chez Proclus, le diadoque platonicien », cité supra (note 133), voir p. 562 (210).

142. Luc Brisson, que je remercie pour sa lecture très attentive de cet article, me fait observer que les néoplatoniciens se savaient sans doute trop peu nombreux pour pouvoir réellement espérer changer le cours des choses. Un argument toutefois qui pourrait aller dans le sens, "optimiste », défendu dans cette conclusion, tient selon lui à la possibilité de déceler une théorie des «cycles» dans la section des Éléments de Théologie de Proclus (Prop. 184 sqq.) qui traite de l'âme. Cette interprétation, proposée à l'occasion de la préparation d'une nouvelle traduction collective des Éléments de Théologie, ménagerait la possibilité d'un cycle nouveau commençant par l'âge de Cronos. 